OPEN ACCESS

Edited by:

Pasqualina Woodrow. University of Campania Luigi Vanvitelli,

Reviewed by:

Muhammad Ahsan Farooq Sri Pratap College Srinagar, India

Parvaiz Ahmad,

Sri Pratap College Srinagar, India

*Correspondence:

Amjad Hameed amjad46pk@yahoo.com

Specialty section: This article was submitted to

Plant Abiotic Stress,

a section of the journal

Frontiers in Plant Science

Received: 28 October 2020 Accepted: 11 February 2021

Published: 11 March 2021

Citation:

Munawar W, Hameed $A$ and

Khan MKR (2021) Differential

Morphophysiological and Biochemical

Responses of Cotton Genotypes Under Various Salinity Stress Levels

During Early Growth Stage.

Front. Plant Sci. 12:622309.

doi: 10.3389/fpls.2021.622309

\section{Differential Morphophysiological and Biochemical Responses of Cotton Genotypes Under Various Salinity Stress Levels During Early Growth Stage}

\author{
Wajeeha Munawar, Amjad Hameed* and Muhammad Khashif Riaz Khan \\ Nuclear Institute for Agriculture and Biology College, Pakistan Institute of Engineering and Applied Sciences, Faisalabad, \\ Pakistan
}

Cotton is a primary agriculture product important for fiber use in textiles and the second major oil seed crop. Cotton is considered as moderately tolerant to salt stress with salinity threshold of $7.7 \mathrm{dS} / \mathrm{m}$ at seedling stage. Salinity causes reduction in the growth of seedlings and cotton production that limits fiber quality and cotton yield. In this study, initially, 22 cotton genotypes were screened for relative salt tolerance using germination test in Petri plates (growth chamber). Selected 11 genotypes were further tested in pot experiment (sand) with 0, 15, and $20 \mathrm{dS} / \mathrm{m} \mathrm{NaCl}$ treatments under glass house conditions. At four-leaves stage, different morphological and physiological traits were measured for all genotypes while biochemical analysis was performed on selected seven highly tolerant and sensitive genotypes. $\mathrm{NaCl}$ treatment significantly reduced plant biomass in two genotypes IR-NIBGE-13 and BS-2018, while NIAB135, NIAB-512, and GH-HADI had least difference in fresh weight between the control and $\mathrm{NaCl}$-treated plants. Photosynthetic rate was maintained in all the genotypes with the exception of SITARA-16. In two sensitive genotypes (IR-NIBGE-13 and 6071/16), $\mathrm{Na}^{+}$ion accumulated more in leaves as compared to $\mathrm{K}^{+}$ion under stress conditions, and an increase in $\mathrm{Na}^{+} / \mathrm{K}^{+}$ratio was also observed. The lesser accumulation of malondialdehyde (MDA) content and higher activity of enzymatic antioxidants such as superoxide dismutase (SOD), peroxidase (POD), and ascorbate peroxidase (APX) in stressed plants of NIAB-135, NIAB-512, and FH-152 indicated that these genotypes had adaption capacity for salinity stress in comparison with sensitive genotypes, i.e., IRNIBGE-13 and 6071/16. The observed salt tolerance was corelated with plant biomass maintenance (morphological), photosynthetic rate, and ionic homeostasis $\left(\mathrm{K}^{+} / \mathrm{Na}^{+}\right.$ratio, physiological) and biochemical stress marker regulations. After a series of experiments, it was concluded that NIAB-135, NIAB-512, and FH-152 could be utilized in breeding programs aimed at improving salinity tolerance in cotton and can expand cotton cultivation in saline area.

Keywords: salt stress, antioxidants, salinity, SOD, CAT, POD, cotton seedlings 


\section{INTRODUCTION}

Soil salinization is rapidly increasing day by day and became a global environmental problem (Ahammed et al., 2018). It decreases average yields of most major crops like wheat, rice, and cotton over and above $50 \%$ on a global scale (Bartels and Sunkar, 2005). The excessive concentration of salt (above from threshold, i.e., 3-4 dS/m) in the soil, water, and plant is called salinity (Hussain et al., 2019). Exposure to salt stress triggers many adverse physiological and biochemical changes in plants leading to yield reduction. Currently, out of $230 \mathrm{~m}$ ha of irrigated land, $45 \mathrm{~m}$-ha area is under the influence of salt (Athar and Ashraf, 2009). Cotton is a primary agriculture crop that covered the biggest textile manufacturing industries devising a strong yearly influence on country economic value of $\$ 600$ billion all over the world (Jabran et al., 2019). The cotton fiber consumption is increasing as human population grows. Gossypium hirsutum (90\%) (high-yielding characteristics and early cultivation system, Campbell et al., 2010) and Gossypium barbadense (8\%) (extralong staple fiber source, Wang et al., 2015) play a very important role in cotton production due to their high yield potential and competitive benefit to cotton textiles producers ( $\mathrm{Hu}$ et al., 2019). According to the 2019 report survey, India, China, United States, Pakistan, Brazil, Australia, Uzbekistan, and Turkey are included in the list of top cottonproducing countries (Ali et al., 2019). Although Pakistan is placed among the globally top 5 cotton-producing countries, on the other hand, its yield lags behind other top most countries due to low yield per unit area and increasing cotton import. However, cotton is proposed as a medium salt-tolerant crop with salinity threshold of $7.7 \mathrm{dS} / \mathrm{m}$ (Maas and Hoffman, 1977). However, low yield, poor plant growth, and germination are the main constraints that are affected by salinity and alkalinity of soil that limit cotton growth at the early stages of development (Ashraf and Ahmad, 2000; Bolek, 2010).

Cotton seed germination is an important phase, but unfortunately, it is also a very sensitive stage for harsh climate conditions. Salinity can hinder seed germination by reducing plant water uptake ability, impose drought to the plant, and deploy it from nutrients by disturbing the ions uptake mechanism (Wang et al., 2011). In salt stress condition, the plant undergoes cellular injury that occurs in transpiring leaves because of large amount of salt accumulation (Khan et al., 1995). It is also considered that the growth rate is directly related with stomatal conductance; the higher the stomatal conductance, the higher will be the $\mathrm{CO}_{2}$ absorption and energy production. However, salt stress decreases $\mathrm{CO}_{2}$ fixation; as a result, reactive oxygen species (ROS) is produced by the leakage of electron into $\mathrm{O}_{2}$ (Ahammed et al., 2018). Cotton growth and plant development comprising plant height, fresh and dry weights, plant weight, root to shoot ratio, leaf area and canopy development, and other physiological parameters like photosynthesis $(\mathrm{Pn})$, transpiration rate $(\mathrm{Tr})$, stomatal conductance $(\mathrm{St})$, overall yield, and primarily fiber quality were severely affected by salinity (Loka et al., 2011). These detrimental effects of salt $(\mathrm{NaCl})$ on cotton differ in accordance with the change in salt concentration (i.e., 10, $20 \mathrm{dS} / \mathrm{m}$, etc.), depending upon the time period of salt exposure (how long it will be) and growth stage in which the plant is exposed to stress (i.e., germination or emergence). Cotton is referred as a salt-tolerant crop after barley, but its yield falls by $5 \%$ per unit $\mathrm{dS} / \mathrm{m}$ with the increase in stress limit (Chinnusamy et al., 2005). Thus, the $200 \mathrm{mM} \mathrm{NaCl}(20 \mathrm{dS} / \mathrm{m})$ stress treatment would induce an approximately $60 \%$ yield reduction underneath the field conditions (Higbie et al., 2010).

Salt stress induced many physiological and biochemical impairments in plants such as photosynthesis, ionic imbalance, and oxidative injury to proteins (enzymes) (Zhu, 2001; Xiong and Zhu, 2002; Muchate et al., 2016). However, the main factor under salt stress condition in cotton is the positive ion $\left(\mathrm{Na}^{+}\right)$instead of $\left(\mathrm{Cl}^{-}\right)$(Gouia et al., 1994). Under salinity stress, the $\mathrm{Na}^{+}$content in the shoots (cotyledon, leaves, and stems) is greater than that in the roots. In leaves, different types of cells have different capacity of sodium accumulation, which is more in the epidermal cell rather than in the mesophyll cell, and this was mainly noted in sensitive genotypes (Peng et al., 2016). Similarly, the salttolerant genotypes have aptitude of maintaining $\mathrm{K}^{+} / \mathrm{Na}^{+}$ratios. For osmotic adjustment, the $\mathrm{Na}^{+}$sequestration into the vacuole is very important in order to minimize the $\mathrm{Na}^{+}$concentration in cell cytoplasm (Maathuis, 2013). For this purpose, $\mathrm{Na}^{+} / \mathrm{H}^{+}$ antiporters (Apse et al., 1999; Shi and Zhu, 2002) V-ATPase and V-PPase [vacuolar (V)], two $\mathrm{H}^{+}$pumps, are involved in $\mathrm{Na}^{+}$compartmentalization into the vacuoles (Dietz et al., 1969). Similarly, the salt-tolerant genotype has more capability of $\mathrm{Na}^{+}$ repossession into the vacuoles. High concentration of $\mathrm{NaCl}$ mainly causes ion toxicity, osmotic stress, and mineral disruption (such as those of $\mathrm{K}^{+}$and $\mathrm{Ca}^{2+}$ ) in plants (Zhu, 2003; Munns and Tester, 2008).

Salt stress also affects the metabolic activities of plant tissues by overproduction of reactive oxygen species (such as $\mathrm{O}^{2-}$, ${ }^{1} \mathrm{O}_{2}$, and $\left.{ }^{\bullet} \mathrm{OH}\right)$ in the cell, which oxidize different biochemical compounds like proteins, lipids, DNA, and RNA and enters the plant into oxidative stress (Munns and Tester, 2008; Miller et al., 2010). Plants possess various extensive antioxidative mechanisms in order to regulate the reactive oxygen species, for instance, ascorbate peroxidase (APX) pathway and superoxide dismutase (SOD) pathway for protection against reactive oxygen destruction. SOD pathway is a first course of action against ROS. It is employed as ROS scavenger to cope with salt stress by converting $\mathrm{O}^{2-}$ into $\mathrm{H}_{2} \mathrm{O}_{2}$ and $\mathrm{O}_{2}$ in roots (Alscher et al., 2002). Similarly $\mathrm{H}_{2} \mathrm{O}_{2}$ could get $\mathrm{H}_{2} \mathrm{O}$ and $\mathrm{O}_{2}$ by reduction reaction in catalase (CAT) pathway confined in peroxisomes organelle (Miller et al., 2010). Peroxidase (POD) is a heme-containing glycoprotein, which catalyzes the $\mathrm{H}_{2} \mathrm{O}_{2}$ in reduction reaction by using different electron donors for example phenolic compounds and secondary metabolites (Hiraga et al., 2001; Zhao et al., 2013). The superoxide dismutase (SOD) activity is enhanced under salt stress. Likewise, malondialdehyde (MDA) content is increased with the rising in lipoxygenase (LOX) activity, as LOX act as a catalyst in the production of fatty acid. Antioxidant enzymes activity like POD and catalase (CAT) is lower in salt-sensitive cultivars than in the tolerant cotton genotypes. In addition, cotton genotypes that are tolerant to salinity exhibit greater activities of SOD, ascorbate, POD, and glutathione reductase with less CAT activity as the amount of salt increases (Jabran et al., 
2019). In cotton, the expression of SOD enhanced with respect to the rise in $\mathrm{NaCl}$ concentration, whereas POD activity is up to $53 \%$ higher in tolerant cultivars. Higher POD activity has improved photosynthesis, which shows the part of antioxidants defense system to alleviate salinity stress (Zhang and Lin, 2014; Sharif et al., 2019). Ascorbate/ascorbic acid is another essential non-enzymatic antioxidant that is higher in the cytoplasm and cell chloroplast when exposed to salt stress. Ascorbic acid has the ability to maintain the photosynthetic apparatus in chloroplast under salinity. In many genotypes, more ascorbic acid in their cell at early growth stages seems to be an indication of tolerance (Aslam et al., 2013).

The present study is designed to screen salt-tolerant genotypes at their seedling stage. As the seedling stage is the most critical stage in proper development of plant systems and processes, therefore, it is important to examine the changes and modifications that arise due to salt stress. The information obtained from this work would be use to identify salt-tolerant and salt-susceptible genotypes and the proper utilization of saline and arid land in order to expand cotton cultivation area. Moreover, this study also provides effective breeding strategies to enhance salt tolerance in cotton.

\section{MATERIALS AND METHODS}

\section{Collection of Cotton Germplasm}

In order to conduct the present study, healthy seeds of 22 genotypes were collected from the Central Cotton Research Institute (CCRI) Multan and Nuclear Institute for Agriculture and Biology (NIAB) Faisalabad (Table 1).

\section{Initial Screening Using Germination Test in Petri Plates}

First of all, the delinted seeds were imbibed in $15 \mathrm{mM}$ aerated $\mathrm{CaSO}_{4} \cdot 2 \mathrm{H}_{2} \mathrm{O}$ for $3 \mathrm{~h}$ and then treated with fungicide $1 \%$ Topsin $\mathrm{M}$ for 2-3 min. After washing the treated seeds with distilled water three times, they were placed on the germination paper (filter) in Petri plates that had been moistened with 0, 7.5, and $15 \mathrm{dS} / \mathrm{m} \mathrm{NaCl}$ solutions. Each plate contained 10 seeds arranged in equal distance, and plates were properly labeled according to

TABLE 1 | List of genotypes used in first experiment (Petri plate).

\begin{tabular}{llcc}
\hline Sr. No. & Genotypes & Sr. No. & Genotypes \\
\hline$(1)$ & ROHI 1 & $(12)$ & CIM-779 \\
$(2)$ & SASUl-2018 & $(13)$ & $6071 / 16$ \\
$(3)$ & SITARA-16 & $(14)$ & FH-326 \\
$(4)$ & MNH-1026 & $(15)$ & FH-152 \\
$(5)$ & MNH-1020 & $(16)$ & IR-NIBGE-13 \\
$(6)$ & CMB-CLEAN COTTON-1 & $(17)$ & GH-HADI \\
$(7)$ & CRIS-671 & $(18)$ & BS-2018 \\
$(8)$ & WEAL-ag-08 & $(19)$ & VH-189 \\
$(9)$ & IUB-69 & $(20)$ & RH-670 \\
$(10)$ & BT-CIM-678 & $(21)$ & NIAB-512 \\
$(11)$ & CIM-602 & $(22)$ & NIAB-135
\end{tabular}

genotype as well as treatment. The Petri plates were placed in a growth chamber at running $29 / 19^{\circ} \mathrm{C}$ (day/night) temperature with light intensity of $550 \mu \mathrm{m} \mathrm{m}^{-2} \mathrm{~s}^{-1} 16 / 8 \mathrm{~h}$ (light/dark) photoperiod. After 4 days, the germination data were recorded. If the emerging radical of the seed was longer than of seed length or the length of radical taken was $\geq 0.5 \mathrm{~cm}$, then it was considered as germinated seed. The Petri plates were kept for 10 days in a growth chamber, and germination data were recorded regularly for analysis. The relative germination rate was calculated as follows:

$\mathrm{RGR}=$ (no. of germinated seed in salt stress condition/no. of germinated seed in control condition) $\times 100 \%$

\section{Germination Parameters}

Final germination (FG), mean germination time (MGT), and germination index (GI) were estimated using the following formulae:

$$
\begin{aligned}
& \mathrm{FG}=\text { (final no. of germinated seed/ } \\
& \text { no. of seeds in Petri plate) } \times 100 \\
& \text { MGT }=(\mathrm{n} 1 \times \mathrm{t} 1+\mathrm{t} 2 \times \mathrm{n} 2+\mathrm{t} 3 \times \mathrm{n} 3 \ldots) / \\
& (\mathrm{n} 1+\mathrm{n} 2+\mathrm{n} 3+\mathrm{n} 4 \ldots)
\end{aligned}
$$

where $\mathrm{n}=$ no. of germinated seed.

$\mathrm{t}=$ germination time interval.

$$
G I=n 1 / d 1+n 2 / d 2+n 3 / d 3 \ldots
$$

where $\mathrm{n}=$ no. of germinated seed.

$\mathrm{d}=1 \mathrm{st}, 2 \mathrm{nd}$, and 3rd day, respectively.

\section{Screening of Salinity Tolerance at Seedling Stage Under Glasshouse Conditions}

Eleven genotypes were selected (including sensitive and tolerant) on the basis of germination parameters, i.e., MGT and GI, etc. through the initial screening of Petri plates experiment. These genotypes were further screened under control and saline conditions with increased salt concentration (Table 2).

Seeds were planted during November 2019 in circular pots (top width, $27 \mathrm{~cm}$; bottom width, $20.5 \mathrm{~cm}$ ) that were filled with $4 \mathrm{~kg}$ sand. All the pots were watered at field capacity before sowing. For sowing, linted seeds were soaked in $15 \mathrm{mM}$ aerated

TABLE 2 | Selected genotypes for seedling experiment under glass house conditions.

\begin{tabular}{llcc}
\hline Sr. No. & Genotypes & Sr. No. & Genotypes \\
\hline$(1)$ & SITARA-16 & $(7)$ & IR-NIBGE-13 \\
$(2)$ & CIM-602 & $(8)$ & GH-HADI \\
$(3)$ & CIM-779 & $(9)$ & BS-2018 \\
$(4)$ & $6071 / 16$ & $(10)$ & NIAB-512 \\
$(5)$ & FH-326 & $(11)$ & NIAB-135 \\
$(6)$ & $\mathrm{FH}-152$ & &
\end{tabular}




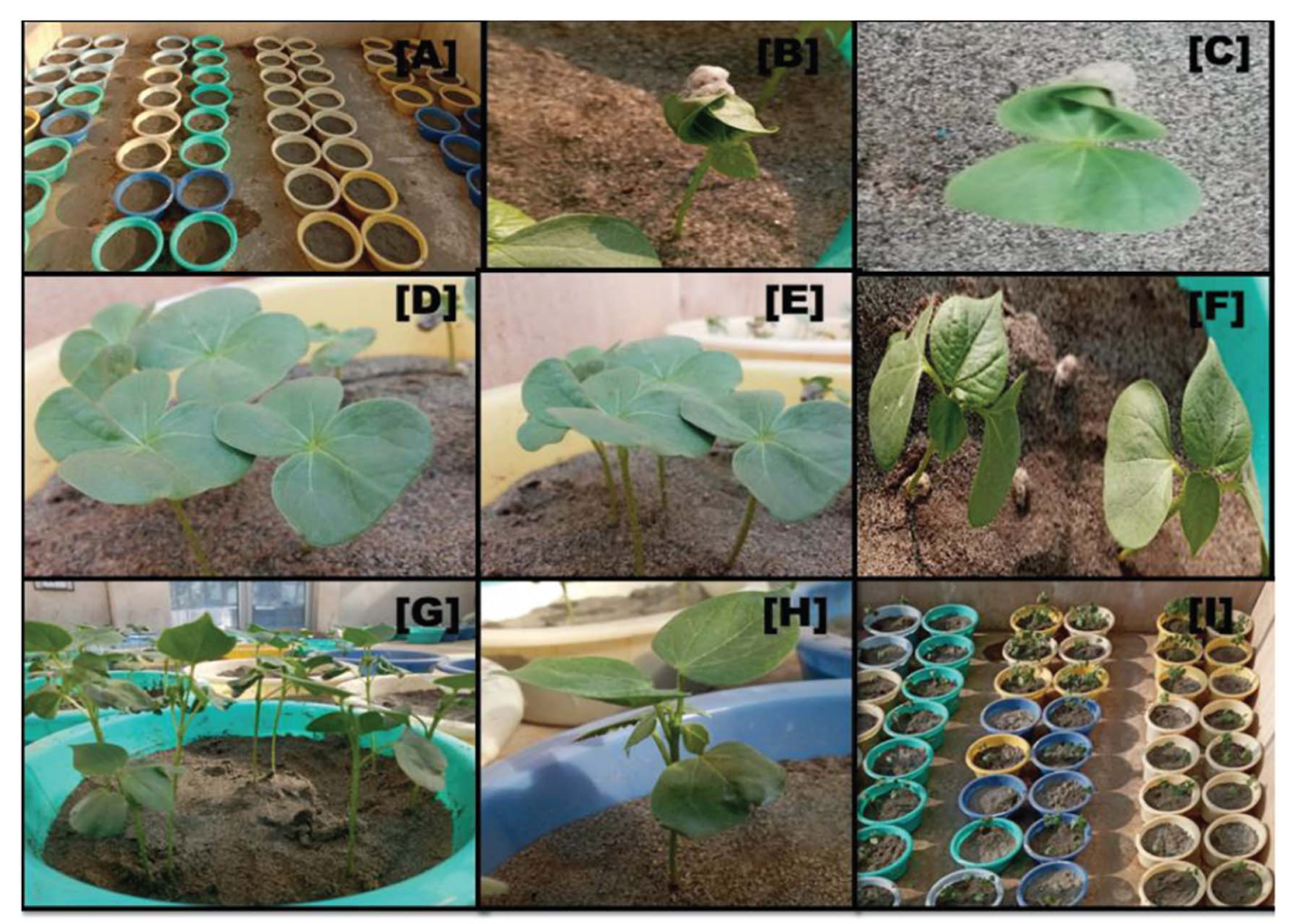

FIGURE 1 | Visual appearance of seedling emergence under glass house conditions: (A) sowing of seeds in sand pots; (B,C) epicotyl emergence of cotyledon leaf 4 DAT sowing; (D,E) full emergence of cotyledon leaves; (F) first and second true leaves emergence; $(\mathbf{G}, \mathbf{H})$ seedlings at fourth true leave stage; and (I) the overall view of sand pots before the day of harvesting.

$\mathrm{CaSO}_{4} \cdot 2 \mathrm{H}_{2} \mathrm{O}$ overnight. In the next morning, 8-10 seeds were sown approximately $2 \mathrm{~cm}$ deep in a sand pot. Every genotype with three replicates and treatments of 0,15 , and $20 \mathrm{dS} / \mathrm{m}$ of $\mathrm{NaCl}$ was maintained in completely randomized design. Glasshouse temperature was kept at $\sim 35^{\circ} \mathrm{C}$ daytime and $\sim 20^{\circ} \mathrm{C}$ nighttime using electric bulbs with a light intensity at $2500 \mathrm{~lx}$ for $14 \mathrm{~h}$. After 3-4 days of sowing, the pots were watered with Hoagland solution of one-eighth strength with field capacity of sand, and this strength was subsequently increased to one-fourth when the cotyledon leaves emerged (Figure 1). When the first true leaves appeared after 15 days of sowing, they were maintained under one-half strength of $\mathrm{NaCl}$-free Hoagland solution until the second true leaf appeared. At the early emergence of the third true leaf, the first salt stress of $50 \mathrm{mM}$ was given, which was increased afterward and maintained one set under $15 \mathrm{dS} / \mathrm{m}(150 \mathrm{mM})$ and another one at $20 \mathrm{dS} / \mathrm{m}(200 \mathrm{mM})$ of $\mathrm{NaCl}$; however, no $\mathrm{NaCl}$ was added to the set that served as control, respectively. After treatment, different physiological traits were recorded between $11 \mathrm{AM}$ and $2 \mathrm{PM}$ on the day before harvesting. Afterward, the plants along with the roots were harvested, and then, different morphological traits were measured.

\section{Morphological Parameters}

At three true leaves stage, the following morphological data were recorded for analysis: The plants of each genotype were rinse with $\mathrm{dH}_{2} \mathrm{O}$ thoroughly, and then, the root and shoot lengths were measured in centimeters. The mean values for each genotype were calculated in each treatment for further analysis. The weight of the whole plant along with roots, shoots, and leaves was measured with the help of weighing balance. After recording the fresh weight, plants were kept in drying oven at $70^{\circ} \mathrm{C}$ for $48 \mathrm{~h}$. Then, dry weights of plants were estimated on an electrical weighing balance.

\section{Physiological Parameters}

Different physiological traits like photosynthesis, stomatal conductance, transpiration, and chlorophyll content were measured by using LI-1600 Steady State Porometer and chlorophyll content by using SPAD-502; $\mathrm{Na}^{+} / \mathrm{K}^{+}$ratio was also measured.

Stomatal conductance $\left(\mathrm{mmol} \mathrm{m}^{-2} \mathrm{~s}^{-1}\right)$ of control and treated plants was recorded with the help of a porometer and then calculated by using the formula:

\section{Stomatal conductance $(\mathrm{Sc})=1 / \mathrm{Dr} \times \mathrm{CF}$}

$\operatorname{Dr}=$ diffusible resistance, which was calculated from the porometer;

$\mathrm{CF}=$ correction factor, which was calculated using formula: LT $\times$ constant. 
The constant value at $25^{\circ} \mathrm{C}$ for durum was 411.8 , and leaf temperature (LT) was also measured by the porometer. In the same manner, stomatal conductance of each control and treatment plants was calculated. Photosynthetic rate $(\mu \mathrm{mol}$ $\mathrm{m}^{-2} \mathrm{~s}^{-1}$ ) was calculated from transpiration rate and stomatal conductance by using the formula:

$$
\begin{aligned}
\mathrm{Phr}=\mathrm{Sc}\left(\mathrm{mmol} \mathrm{m}^{-2} \mathrm{~s}^{-1}\right) / \operatorname{Tr}\left(\mu \mathrm{g} \mathrm{cm}^{-2} \mathrm{~s}^{-1}\right) \times 10 \\
\mathrm{Sc}=\text { stomatal conductance; } \mathrm{Tr}=\text { transpiration rate. }
\end{aligned}
$$

Transpiration rate $\left(\mathrm{mmol} \mathrm{m} \mathrm{m}^{-2} \mathrm{~s}^{-1}\right)$ was measured in $\mu \mathrm{g}$ $\mathrm{cm}^{-2} \mathrm{~s}^{-1}$, as relative value was calculated by the transpiration value from the porometer divided by 10,000 and multiplied with 1000. A chlorophyll meter (Model: SPAD 502 plus Japan) was used to measure the chlorophyll contents in the leaves before and after salt stress. The chlorophyll meter SPAD was placed on the uppermost leaf of a plant to measure the chlorophyll. The day before harvesting, physiological data were recorded for analysis under control and saline conditions.

\section{$\mathrm{Na}^{+} / \mathrm{K}^{+}$Ratio}

Sodium $\left(\mathrm{Na}^{+}\right)$and potassium $\left(\mathrm{K}^{+}\right)$concentrations were measured on a flame photometer (Model; Jenway PFP 7). First of all, to digest dried ground material, $0.05 \mathrm{~g}$ of the leaf material was taken in digestion tubes. Then, $1 \mathrm{ml}$ of conc. $\mathrm{H}_{2} \mathrm{SO}_{4}$ was added on the dried sample for the sake of digestion. All the tubes were kept in the dark for overnight incubation at room temperature. The next day, $0.5 \mathrm{ml}$ of $\mathrm{H}_{2} \mathrm{O}_{2}$ (35\%) was added, and the tubes were shifted in a digestion block and heated at $350^{\circ} \mathrm{C}$ up to the production of fumes. After $30 \mathrm{~min}$ of heating, the digestion tubes were removed from the block to cool down. $\mathrm{H}_{2} \mathrm{O}_{2}$ $(0.5 \mathrm{ml})$ was added gradually, and the tubes were positioned back into the digestion block. The above mentioned step was repeated until the color of the digestion material turned transparent. Then, the volume of the digestion extract made up $25 \mathrm{ml}$ of the volumetric flasks. After the extract was filtered, it used to analyze $\mathrm{K}^{+}$and $\mathrm{Na}^{+}$.

\section{Stress Susceptibility Index}

Stress susceptibility index (SSI) was calculated for the tested genotypes under 15 and $20 \mathrm{dS} / \mathrm{m}$ salt stress and non-stress conditions by using this formula (Fischer and Maurer, 1978):

$$
\mathrm{SSI}=1-(\mathrm{Ys} / \mathrm{Yp}) / \mathrm{SI}
$$

Ys = means of characters under salt stress conditions;

$\mathrm{Yp}=$ mean of character under non-stress condition.

While for stress intensity (SI):

$$
\mathrm{SI}=1-(\hat{\mathrm{Y}} \mathrm{s} / \hat{\mathrm{Y}} \mathrm{p})
$$

$\hat{Y} s=$ means of all the genotypes under stress conditions.

$\hat{Y} \mathrm{p}=$ means of all the genotypes under non-stress condition.

\section{Stress Tolerance Index}

Stress tolerance index (STI) was calculated for the determination of stress tolerance potential of genotypes under 15 and $20 \mathrm{dS} / \mathrm{m}$ salt stress and non-stress conditions by using following formulae (Fernandez, 1993):

Root length STI = (root length of stressed plant $/$ root length of non-stressed plant) $\times 100$

Shoot length STI = (shoot length of stressed plant/shoot length of non-stressed plant $) \times 100$

Stomatal conductance STI $=$ (stomatal conductance of stressed plant/stomatal conductance of non-stressed plant) $\times 100$

Photosynthetic rate STI $=$ (photosynthetic rate of stressed plant/photosynthetic rate of non-stressed plant $) \times 100$

Transpiration rate STI $=$ (transpiration rate of stressed plant/transpiration rate of non-stressed plant $) \times 100$ Chlorophyll content STI $=$ (chlorophyll content of stressed plant/vhlorophyll content of non-stressed plant) $\times 100$

\section{Biochemical Analysis}

After morphophysiological analysis, treatment-induced biochemical modifications in plant leaves were analyzed. The genotypes were selected on the basis of variance analysis of morphophysiological parameters, SSI and STI; the two sensitive and five tolerant genotypes were selected and further tested by biochemical analysis (Table 3).

\section{Extraction for Antioxidant Enzyme Activities}

First of all, after weighing, $0.1 \mathrm{~g}$ fresh leaf from all cotton genotypes was extracted in $1 \mathrm{ml}$ of $50 \mathrm{mM}$ potassium phosphate buffer with $\mathrm{pH} 7.4$, and then, ground samples were centrifuged at $14,000 \times g$ for $10 \mathrm{~min}$ at $4^{\circ} \mathrm{C}$. The resultant supernatant was separated and utilized for determination of different enzymatic and non-enzymatic analysis. All the data were taken in duplicate.

\section{Enzymatic Antioxidants \\ Ascorbate oxidase activity}

For estimation of APX activity, leaf sample was homogenized in $50 \mathrm{mM}$ potassium phosphate buffer, and APX was measured using the method explained by Dixit et al. (2001). The required reagent R1 assay buffer was prepared by using $0.2 \mathrm{M}$ potassium phosphate buffer ( $\mathrm{pH} 7.0$ ), $10 \mathrm{mM}$ of ascorbic acid, and then $20 \mathrm{ml}$ of $0.5 \mathrm{M}$ ethylenediaminetetraacetic acid (EDTA) mixing to get assay buffer. The second reagent $\mathrm{R} 2$ was $4 \mathrm{mM} \mathrm{H}_{2} \mathrm{O}_{2}$, and then the sample was extracted. For the estimation of APX activity,

TABLE 3 | Selective sensitive and tolerant genotypes for biochemical analysis.

\begin{tabular}{lccc}
\hline Sr. No. & Genotypes & Sr. No. & Genotypes \\
\hline$(1)$ & $6071 / 17$ & $(5)$ & IR-NIBGE-13 \\
$(2)$ & $\mathrm{FH}-326$ & $(6)$ & GH-HADI \\
$(3)$ & $\mathrm{FH}-512$ & $(7)$ & NIAB-512 \\
$(4)$ & $\mathrm{NIAB}-135$ & &
\end{tabular}


$1 \mathrm{ml}$ assay buffer and $50 \mu \mathrm{l}$ sample were added, and the reaction was initiated after adding $1 \mathrm{ml}$ of $10 \% \mathrm{H}_{2} \mathrm{O}_{2}$. The decrease in oxidation rate of ascorbic acid in absorbance at $290 \mathrm{~nm}$ after every $30 \mathrm{~s}$ was measured.

\section{Superoxide dismutase activity}

First, cotton leaves were ground in $50 \mathrm{mM}$ potassium phosphate buffer (pH 7.0), 0.1 mM EDTA, and $1 \mathrm{mM}$ dithiothreitol (DTT) as described in Dixit et al. (2001). For estimation of SOD activity, the samples after adding reagents [400 $\mu \mathrm{l}$ water, $250 \mu \mathrm{l}$ of 0.2 $\mathrm{M}$ potassium phosphate buffer, $100 \mu \mathrm{L}$ L-methane, $100 \mu \mathrm{l}$ Triton $\mathrm{X}, 100 \mu \mathrm{l}$ nitroblue tetrazolium (NBT)] were kept under the white light for $10 \mathrm{~min}$. SOD activity was analyzed by assessing its ability to prevent the photochemical reduction in NBT that is present in chemical reagents, as explained in the method in Giaanopolitis and Ries (1977). Thus, $1 \mathrm{U}$ of SOD activity is explained by the amount that produced $50 \%$ resist photochemical reduction in NBT.

\section{Peroxidase activity}

In order to analyze the POD activity, cotton leaves were homogenized in $50 \mathrm{mM}$ potassium phosphate buffer having $\mathrm{pH}$ 7.0 and POD activity estimated by using this method (Maehly and Chance, 1955) with certain amendments. Thus, as to POD measurement, the assay solution prepared by mixing distilled water $(535 \mu \mathrm{l}), 200 \mathrm{mM}$ phosphate buffer with $\mathrm{pH}$ 7.0, $200 \mathrm{mM}$ guaiacol, $400 \mathrm{mM} \mathrm{H} \mathrm{H}_{2} \mathrm{O}_{2}$, and $15 \mu \mathrm{l}$ extracted sample. After adding the enzyme extract, reaction was began and absorbance at $470 \mathrm{~nm}$ was recorded after every $20 \mathrm{~s}$. The increasing trend in absorbance was observed, and enzyme activity was explained on the basis of leaves weight. Thus, $1 \mathrm{U}$ of POD activity was defined as an absorbance change of $0.01 / \mathrm{min}$.

\section{Catalase activity}

For the estimation of catalase activity, cotton leaves were emulsified in $50 \mathrm{mM}$ potassium phosphate buffer ( $\mathrm{pH} 7.0$ ) and $1 \mathrm{mM}$ dithiothreitol (DTT), and estimation was done by the method explained by Beers and Sizer (1952). The required assay solution for CAT activity contained $50 \mathrm{mM}$ potassium phosphate buffer with same $\mathrm{pH} 7.0,59 \mathrm{mM} \mathrm{H}_{2} \mathrm{O}_{2}$, and $0.1 \mathrm{ml}$ sample (enzyme extract). The reaction was started after adding the sample and decreasing pattern in absorbance at $240 \mathrm{~nm}$ was recorded after every $20 \mathrm{~s}$. Thus, $1 \mathrm{U}$ of CAT activity described as change in absorbance of $0.01 / \mathrm{min}$ and enzyme activity expressed on the basis of leaves weight.

\section{Total antioxidant capacity}

The reagent 1 (R1), $400 \mathrm{mmol} / \mathrm{l}$ acetate buffer solution ( $\mathrm{pH} 5.8$ ), was prepared by suspending $54.432 \mathrm{~g}$ of $\mathrm{CH}_{3} \mathrm{COONa} .3 \mathrm{H}_{2} \mathrm{O}$ in $1 \mathrm{~L}$ deionized water. A $60-\mathrm{ml}$ acetic acid was mixed with sodium acetate solution. The reagent 2 (R2), $30 \mathrm{mmol} / \mathrm{l}$ acetate buffer solution ( $\mathrm{pH} 3.6$ ), was prepared by adding $2.46 \mathrm{~g} \mathrm{CH}_{3} \mathrm{COONa}$ suspended in $1 \mathrm{~L}$ of deionized water. Acetic acid after dilution was mixed with sodium acetate solution. Then, $278 \mu$ l was removed from $\mathrm{R} 2$, and the same amount was added from $35 \%$ of $\mathrm{H}_{2} \mathrm{O}_{2}$ solution. 2,2'-Azinobis-3-ethylbenzthiazolin-6sulfonic acid (ABTS) (0.549 g) was suspended in $100 \mathrm{ml}$ of already equipped solution (final concentration, $10 \mathrm{mmol} / \mathrm{L}$ ). The characteristic color of ABTS appeared after incubation for $1 \mathrm{~h}$ at room temperature. Colored reagent is unstable for 6 months if stored at $4^{\circ} \mathrm{C}$. The first absorbance of this assay was taken before mixing R1 and R2, which served as blank, and the next absorbance was measured after mixing R1 and R2 (after 5 min incubation at room temperature).

\section{Non-enzymatic Antioxidants \\ Total phenolic content}

A total phenolic content (TPC) estimation method as explained in Ainsworth and Gillespie (2007) was applied with certain modifications in order to estimate TPC. First of all, $0.05 \mathrm{~g}$ of leaves sample was weighed, and for homogenization, it was placed in the dark for $48 \mathrm{~h}$ after adding $500 \mu \mathrm{l}$ chilled 95\% methanol and then centrifuged at $14,000 \times g$ for $5 \mathrm{~min}$. The supernatant was separated and used for TPC estimation. The assay protocol was as follows: $150 \mu \mathrm{l}$ of $10 \%(\mathrm{v} / \mathrm{v}) \mathrm{F}-\mathrm{C}$ reagent mixed with $100 \mu \mathrm{l}$ sample vortex thoroughly and then added $1.2 \mathrm{ml}$ of $700 \mathrm{mM} \mathrm{Na} \mathrm{CO}_{3}$. Then, samples were left for $1 \mathrm{~h}$ incubation at room temperature. Blank corrected absorbance of samples was recorded at $765 \mathrm{~nm}$. Phenolic content (gallic acid equivalents) of samples was determined by using linear regression equation.

\section{Tannins}

The supernatant from TPC assay was not discarded after recording readings from a spectrophotometer. PVP.P $(0.1 \mathrm{~g})$ was added in TPC samples and vortexed for 2-3 min. Then, these samples were centrifuged at $14,000 \times g$, and the supernatant was used for absorbance at $765 \mathrm{~nm}$ so as to estimate tannins in cotton leaves sample.

\section{Ascorbic acid}

The 2,6-dichloroindophenol (DCIP) method was used for ascorbic acid determination as explained by Hameed et al. (2005). For concise description, each molecule of vitamin $\mathrm{C}$ converted DCIP molecule into $\mathrm{DCIPH}_{2}$ molecule, and this reaction was examined as a decreasing trend in absorbance at $520 \mathrm{~nm}$ was observed. A standard curve and linear regression equation was used to find the ascorbate concentration in the samples.

\section{Alpha amylase activity}

The alpha amylase activity of the cotton leaves was determined by the method in Varavinit et al. (2002) with certain modifications. Two reagents were required for $\alpha$-amylase estimation. One is 3,5dinitrosalicyclic acid (DNS) (prepared with $1 \mathrm{~g}$ DNS in $\mathrm{dH}_{2} \mathrm{O}$, then added $30 \mathrm{~g}$ of sodium potassium tatrate tetrahydride, and $20 \mathrm{ml}$ of $2 \mathrm{~N} \mathrm{NaOH}$ made up volume up to $100 \mathrm{ml}$ ), and the second was $1 \%$ starch solution. After adding $0.2 \mathrm{ml}$ sample and $1 \%$ starch solution, the reaction mixture was incubated for $3 \mathrm{~min}$ and placed in water bath for 15 min after adding DNS, and then made up volume up to $9 \mathrm{ml}$ with $\mathrm{dH}_{2} \mathrm{O}$. Absorption was observed at $540 \mathrm{~nm}$ spectrometrically.

\section{Reducing sugars (sugar content)}

The reducing sugar level in cotton leaves was estimated by using dinitrosalicyclic acid method explained in Miller (1959). Thus, the total soluble sugar contents of cotton leaves were also measured by phenol-sulfuric acid reagent method (Dubois et al., 

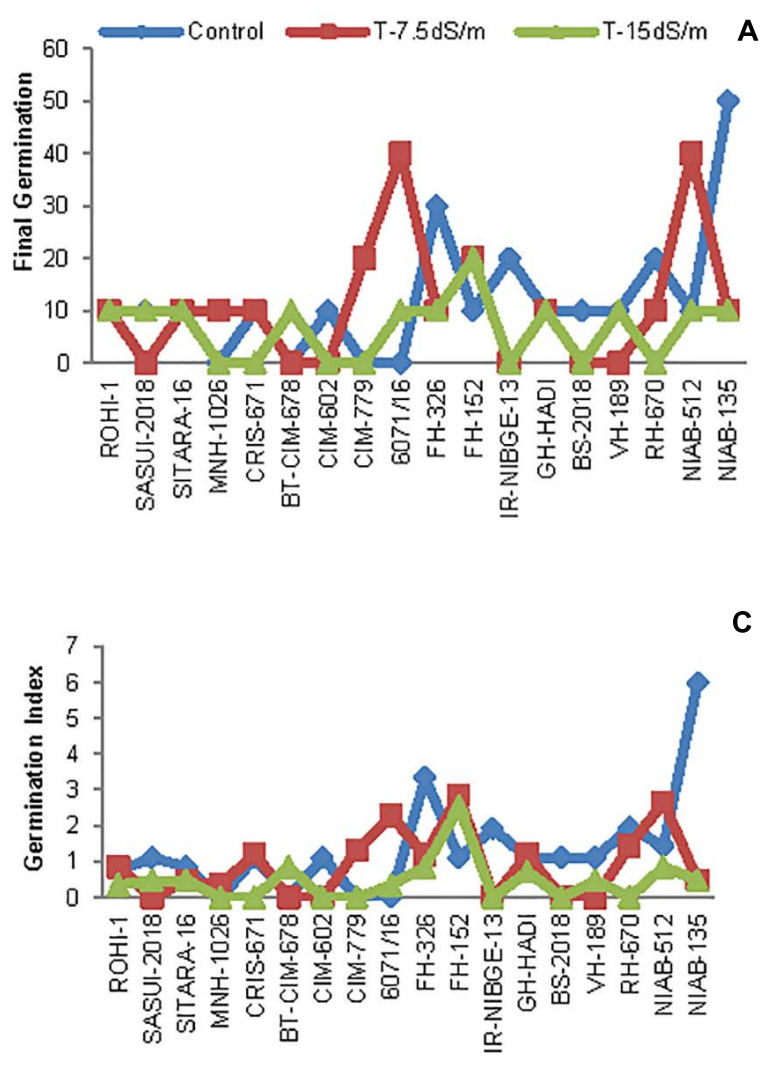

C

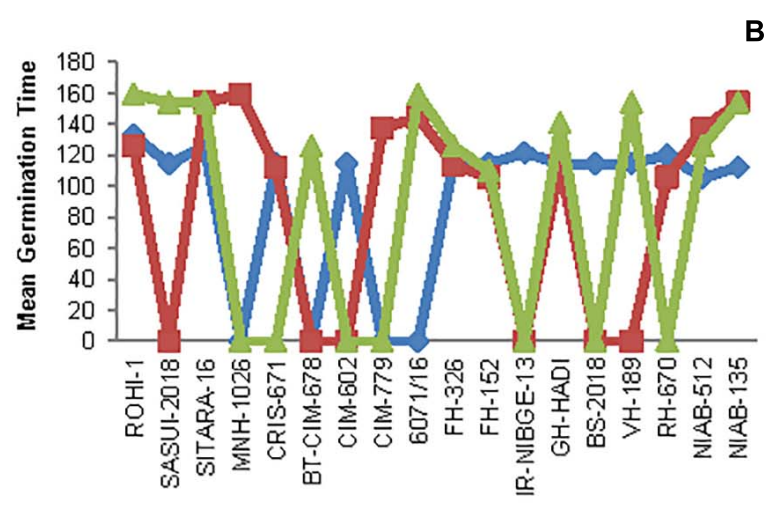

B

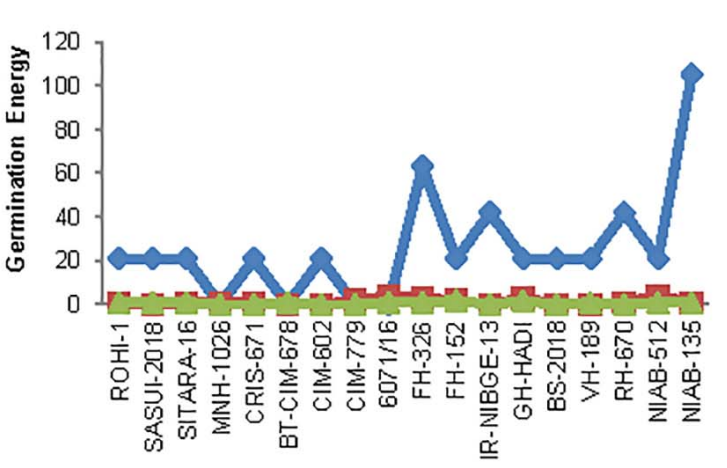

FIGURE 2 | (A) Final seed germination of cotton, (B) mean germination time (MGT), (C) germination index (GI), and (D) germination energy (GE) in growth chamber under control and salt stress conditions.

1956). In this way, the non-reducing sugars were determined by the difference in reducing and total soluble sugars.

\section{Other Biochemical Parameters \\ Pigment analysis}

The amount of chlorophyll ( $\mathrm{a}$ and $\mathrm{b}$ ) and carotenoids was calculated by using method described in Arnon (1949). In the first step, $0.075 \mathrm{~g}$ of cotton leaves samples was homogenized in $80 \%$ chilled acetone and incubated at room temperature for $24 \mathrm{~h}$ in dark. After $24 \mathrm{~h}$, it was centrifuged at $14,000 \times g$ for $5 \mathrm{~min}$. Absorbance of supernatant was measured at 645, 663, 505, 453 , and $470 \mathrm{~nm}$.

\section{Total oxidant status}

Total oxidant status (TOS) in cotton leaves samples was determined by the method described in Erel (2005). This method is based on the oxidation of $\mathrm{Fe}^{+2}$ ions into $\mathrm{Fe}^{+3}$ by oxidants that are present in the sample acidic medium and measurement of ferric ions by xylenol orange. The assay mixture contained reagent $\mathrm{R} 1$, which is stock xylene orange solution containing $0.38 \mathrm{~g}$ in $500 \mu \mathrm{l}$ of $25 \mathrm{mM} \mathrm{H}_{2} \mathrm{SO}_{4}, 0.4 \mathrm{~g}$ of $\mathrm{NaCl}, 500 \mu \mathrm{l}$ of glycerol, and volume up to $50 \mathrm{ml}$ with $25 \mathrm{mM} \mathrm{H}_{2} \mathrm{SO}_{4}$. The reagent $\mathrm{R} 2$ contained $0.0317 \mathrm{~g}$ of $\mathrm{o}$-dianisidine and $0.0196 \mathrm{~g}$ of ferrous ammonium sulfate and sample extract. After $5 \mathrm{~min}$ of adding R2, the absorption was measured at $560 \mathrm{~nm}$ by using a spectrophotometer. A standard curve was prepared using hydrogen peroxide. The results were expressed in $\mu \mathrm{M} \mathrm{H} \mathrm{H}_{2} \mathrm{O}_{2}$ equivalent per $\mathrm{L}$.

\section{Total soluble proteins}

To determine the protein content, leaves samples were homogenized in a medium of potassium phosphate buffer. Quantitative protein determination was done by using the method Bradford (1976). The assay protocol contained $5 \mu \mathrm{l}$ of supernatant of the sample extract, $0.1 \mathrm{~N} \mathrm{NaCl}$, and then mixed with $1.0 \mathrm{ml}$ of Bradford dye. This mixture was kept for 5 min to form protein dye complex before taking readings. Blank-corrected reading was calculated at $595 \mathrm{~nm}$ by a spectrophotometer.

\section{Malondialdehyde content}

The lipid peroxidation level in cotton leaves was assessed regarding MDA (a product from lipid peroxidation) content measured by thiobarbituric acid (TBA) method described in Heath and Packer (1968) with slight modification of the method in Dhindsa et al. (1981). The 0.1-g leaves sample was homogenized in $0.1 \%$ TCA. This extract was centrifuged at $14,000 \times g$ for $5 \mathrm{~min}$. To $1 \mathrm{ml}$ aliquot of the supernatant, $20 \%$ TCA containing $0.05 \%$ TBA was added. The mixture was heated at $95^{\circ} \mathrm{C}$ for $30 \mathrm{~min}$ and then quickly cooled in an ice bath. After centrifuging at $14,000 \times g$ for $10 \mathrm{~min}$, the absorbance of the 


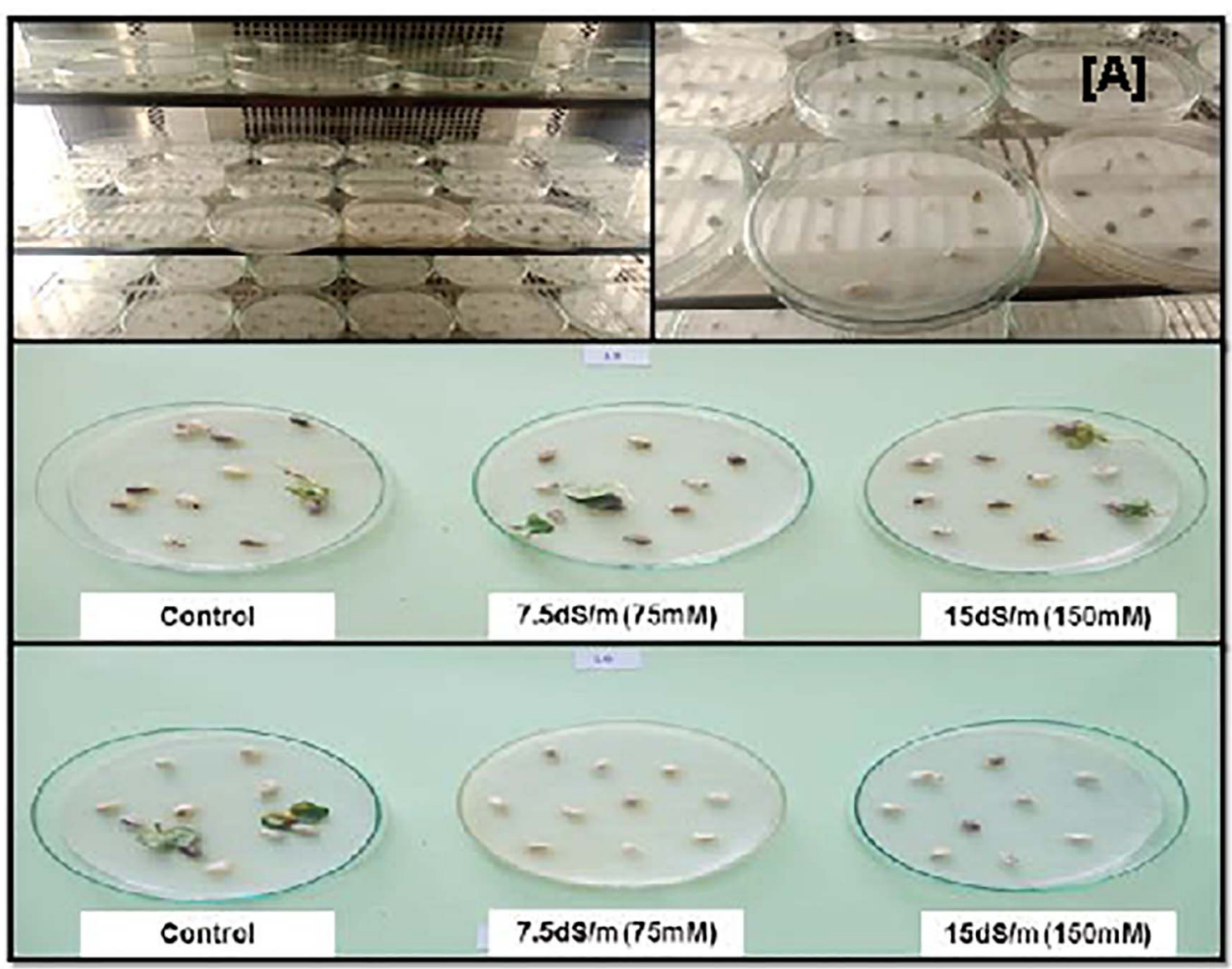

FIGURE 3 | (A) Cotton seeds germination in growth chamber under salinity stress and normal condition. The tolerant cotton seed germination occurs in both salt stresses but no germination in sensitive genotypes.

supernatant was recorded at $532 \mathrm{~nm}$, and the value for the nonspecific absorption at $600 \mathrm{~nm}$ was subtracted. The MDA content was estimated by using extinction coefficient of $155 \mathrm{mM}^{-1} \mathrm{~cm}^{-1}$.

\section{Total flavonoids}

The total flavonoid (TF) content was determined by using aluminum chloride colorimetric method (Ainsworth and Gillespie, 2007). Each sample extract was mixed with $0.1 \mathrm{ml}$ of $10 \%$ aluminum chloride hexadihydrate, $0.1 \mathrm{ml}$ of $1 \mathrm{M}$ potassium acetate and $2.8 \mathrm{ml}$ of deionized water. After $40 \mathrm{~min}$ of incubation at the room temperature, the absorbance of the sample was determined by a spectrophotometer at $415 \mathrm{~nm}$.

\section{Statistical Analysis}

Data were presented in the graphs as mean values and standard error. Statistical analysis was based on variance analysis and Tukey [honestly significant difference (HSD)] test at $\mathrm{p}<0.05$. The different letters above the bars in the same genotypes under stress and non-stress conditions indicated significant differences with tolerance 0.0001. Bars with similar letters in the same genotypes under treatments were non-significant. Principal component analysis (PCA) and correlation (Pearson test) were performed by using XL-STAT 2012.1.02 with 95\% confidence interval. Cluster analysis was also performed by agglomerative hierarchical clustering (AHC) of cotton genotypes under control and salt stress conditions.

\section{RESULTS}

\section{Seed Germination Test}

The initial screening was done at seed germination stage. In this experiment, seeds were tested against $0,7.5$, and $15 \mathrm{dS} / \mathrm{m}$ salt stress. Genotypes with $0 \%$ germination even in control, i.e., MNH-1020, CMB-CLEAN-COTTON, WEAL-AG-08, and IUB-69, were excluded. Salt stress inhibited seed germination in many genotypes. In NIAB-512, seed germination percentage remained the same as in control and under $15 \mathrm{dS} / \mathrm{m}$, but $30 \%$ germination was increased under $7.5 \mathrm{dS} / \mathrm{m}$ salt stress condition. Similarly, 6071/16 also showed increase in 30\% germination under $7.5 \mathrm{dS} / \mathrm{m}$, and both genotypes behaved as moderately tolerant. In IR-NIBGE-13, seed germination occurred in control but not under stress conditions and was regarded as sensitive genotype at germination stage. The seed germination was slightly attenuated by salt stress in NIAB-135, as only $20 \%$ germination 

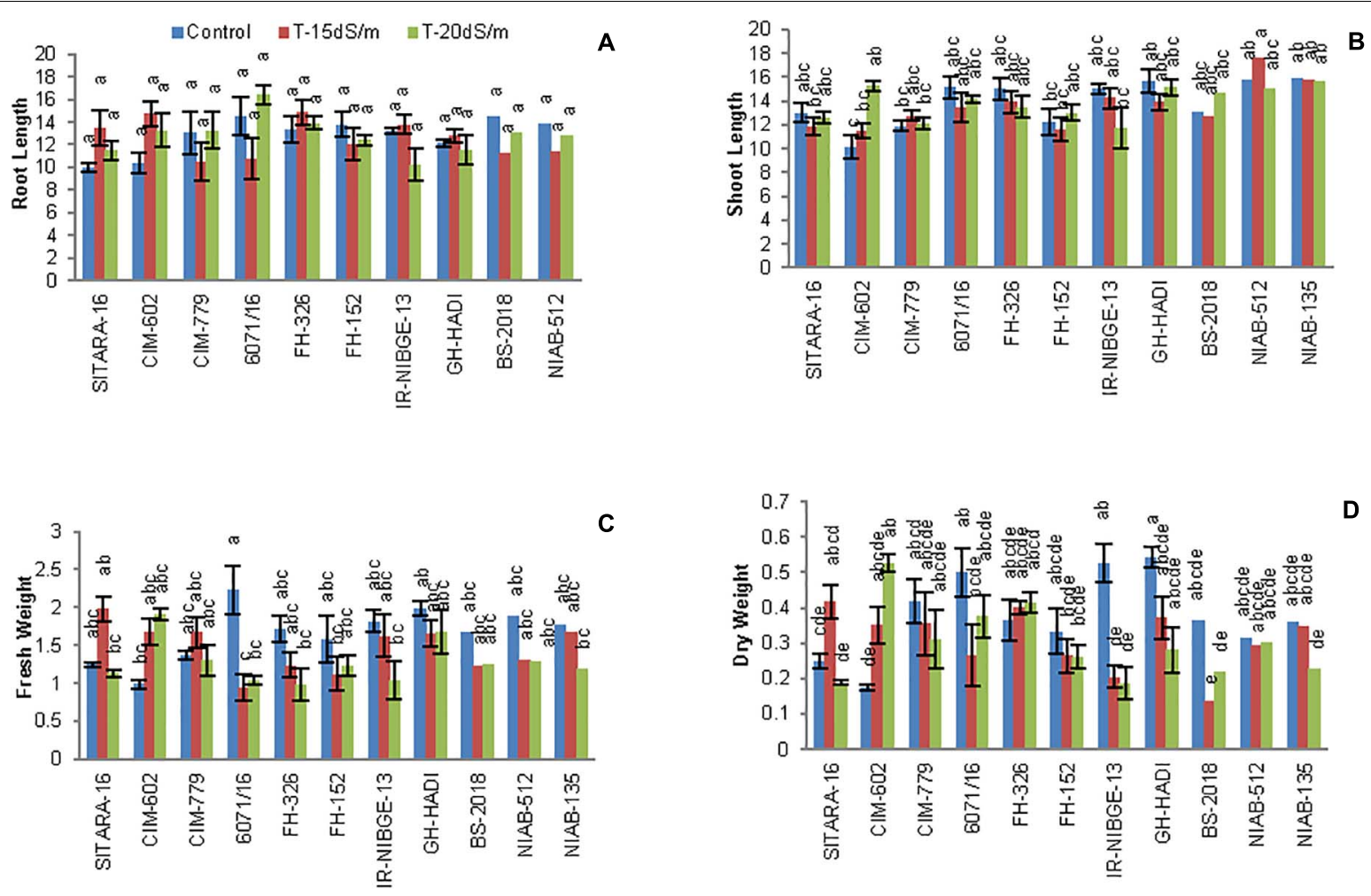

FIGURE 4 | Comparison of panels (A) root length, (B) shoot length, (C) fresh weight, and (D) dry weight between cotton genotypes under control and salt stress conditions.

occurred. Moreover, in FH-152, germination was increased by 20\% under stress conditions (Figures 2A, 3).

The relative increase in mean germination time (MGT) was observed in ROHI-1, SITARA-16, FH-326, 6071/16NIAB-135, and NIAB-512 under stress conditions as compared to that under non-stress condition. Salt stress showed no significant effect in FH-152, as MGT of seeds remained the same under control and stress conditions (Figure 2B).

Salt stress significantly decreased germination index (GI) in FH-326 and NIAB-135. The maximum GI was recorded in NIAB-135, afterward in FH-326, under non-stress condition. In contrast, GI was increased in FH-152 under stress conditions. However, the least differences between control and stress were observed in ROHI-1, SITARA-16, and NIAB-512 (Figure 2C).

In addition, seed germination energy (GE) was highly retarded by salt stress. An increased in GE was observed more under nonstress as compared to salt stress conditions in all the genotypes. The maximum GE was recorded in NIAB-135 and then in FH326 under non-stress condition (Figure 2D).

\section{Morphological Parameters}

\section{Root and Shoot Lengths}

The growth parameters root and shoot lengths were not significantly affected by $\mathrm{NaCl}$ treatment, with the exception of CIM-602 and NIAB-512 in which the shoot length was significantly increased compared to that in non-stress condition.
However, most of the genotypes had not shown considerable changes in root and shoot lengths (Figures 4A,B, 5).

On the basis of STI, CIM-602, GH-HADI, and FH-326 found to be tolerant genotypes for root length under stress conditions. All the accessions were also cross-checked with SSI. Under $20 \mathrm{dS} / \mathrm{m}$ salt stress conditions, IR-NIBGE-13 and FH-152 were found to be susceptible for root length (Table 4). Similarly, CIM602, NIAB-512, NIAB-135, CIM-779, and FH-326 showed more STI values for shoot length under stress conditions.

\section{Plant Fresh and Dry Weights}

In cotton plants, $\mathrm{NaCl}$ treatment significantly reduced plant biomass in two genotypes IR-NIBGE-13 and BS-2018. A similar trend was also noted in other genotypes. However, NIAB-135, NIAB-512, and GH-HADI had the least difference in fresh weight between non- $\mathrm{NaCl}$ and $\mathrm{NaCl}$-treated plants (Figures 4C,D).

Plant fresh weight was significantly reduced in 6071/16. Similarly, on the basis of SSI and STI, 6071/16 found to be susceptible for fresh weight and IR-NIBGE-13, 6071/16, and BS2018 for dry weight under stress conditions. The fresh and dry weights were least affected by salt stress in NIAB-512 and NIAB135 , with the exception of NIAB-135, which showed susceptibility under $20 \mathrm{dS} / \mathrm{m}$ salt stress for dry weight. Although salt stress had a significant effect on plant biomass, FH-152, FH-326, NIAB-512, and NIAB-135 improved significantly by maintaining their dry weights compared to that under control (Table 5). 

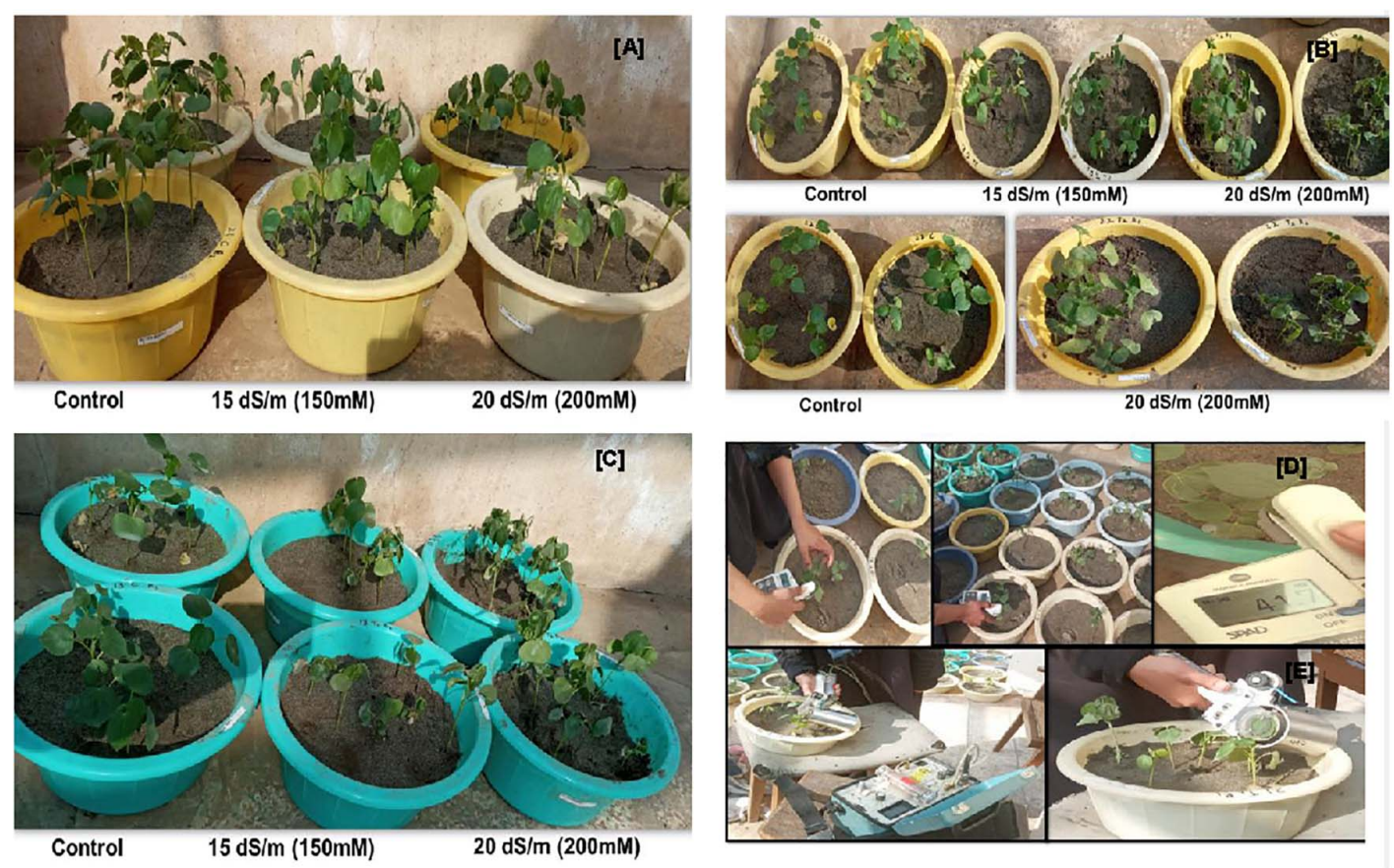

FIGURE 5 | Pictorial view of panels (A) NIAB-512, (B) NIAB-135, and (C) 6071/16 under control and salt stress conditions (sand pot in glass house) at fourth true leave stage. Schematic diagram of recording physiological parameters: Measuring chlorophyll content by using (D) SPAD and stomatal conductance, transpiration, and photosynthetic rate before harvesting by using $(\mathbf{E})$ porometer.

TABLE 4 | Stress susceptibility and tolerance indices for shoot and root lengths.

\begin{tabular}{|c|c|c|c|c|c|c|c|c|}
\hline \multirow[t]{2}{*}{ Genotypes } & \multicolumn{4}{|c|}{ Shoot length } & \multicolumn{4}{|c|}{ Root length } \\
\hline & SSI-T1 & SSI-T2 & STI-T1 & STI-T2 & SSI-T1 & SSI-T2 & STI-T1 & STI-T2 \\
\hline SITARA-16 & 3.832776 & -176.308 & 0.913462 & 0.971154 & -9.18668 & -22.7716 & 1.35 & 1.15 \\
\hline CIM-602 & -6.01467 & 3093.728 & 1.135802 & 1.506173 & -11.0683 & -42.0681 & 1.421687 & 1.277108 \\
\hline CIM-779 & -3.26346 & 128.6737 & 1.073684 & 1.021053 & 5.047628 & -2.91944 & 0.807692 & 1.019231 \\
\hline $6071 / 16$ & 4.758414 & -404.099 & 0.892562 & 0.933884 & 6.788189 & -19.6307 & 0.741379 & 1.12931 \\
\hline $\mathrm{FH}-326$ & 3.321739 & -611.2 & 0.925 & 0.9 & -2.94366 & -5.67517 & 1.11215 & 1.037383 \\
\hline $\mathrm{FH}-152$ & 2.259686 & 374.2041 & 0.94898 & 1.061224 & 3.340612 & 15.18108 & 0.872727 & 0.9 \\
\hline IR-NIBGE-13 & 2.214493 & -1324.27 & 0.95 & 0.783333 & -0.99048 & 34.37226 & 1.037736 & 0.773585 \\
\hline GH-HADI & 4.960464 & -195.584 & 0.888 & 0.968 & -1.35297 & 7.8253 & 1.051546 & 0.948454 \\
\hline BS-2018 & 1.265424 & 698.5143 & 0.971429 & 1.114286 & 5.883097 & 14.39585 & 0.775862 & 0.905172 \\
\hline NIAB-512 & -5.2726 & -291.048 & 1.119048 & 0.952381 & 4.729309 & 12.30898 & 0.81982 & 0.918919 \\
\hline NIAB-135 & 0.556231 & -86.3548 & 0.987441 & 0.985871 & 4.721207 & 5.526304 & 0.820128 & 0.963597 \\
\hline
\end{tabular}

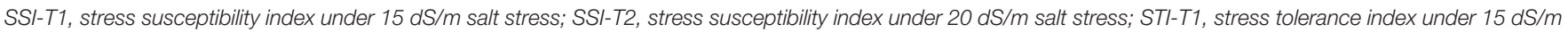
salt stress; STI-T2, stress tolerance index under $20 \mathrm{dS} / \mathrm{m}$ salt stress.

\section{Physiological Parameters Stomatal Conductance and Photosynthetic Rate}

Salt stress significantly decreased stomatal conductance in IR-NIBGE-13, 6071/16, GH-HADI, and FH-152 (Figure 6). However, stomatal conductance was maintained in NIAB-135, NIAB-512, SITARA-16, and FH-326 under stress and non-stress conditions (Table 6). Photosynthetic rate was maintained in all the genotypes with the exception of SITARA-16 and CIM-602. Based on SSI, IR-NIBGE-13 was found to be more sensitive under $20 \mathrm{dS} / \mathrm{m}$ salt stress condition (Table 7).

\section{Transpiration Rate and Chlorophyll Content}

Mostly in genotypes, salt stress decreased the transpiration rate. However, the least differences of salt stress for transpiration rate were observed in FH-326. Nevertheless, in 6071/16, transpiration rate was observed as increased under $15 \mathrm{dS} / \mathrm{m}$ salt stress. Thus, on the basis of SSI and STI, 6071/16 was found to be slightly tolerant under $15 \mathrm{dS} / \mathrm{m}$ but sensitive for severe $20 \mathrm{dS} / \mathrm{m}$ salt stress. Similarly, transpiration rate was significantly decreased in IR-NIBGE-13 under $20 \mathrm{dS} / \mathrm{m}$ salt stress. However, NIAB-512 and NIAB-135 maintained transpiration 
TABLE 5 | Stress susceptibility and tolerance Indices for fresh and dry weights.

\begin{tabular}{|c|c|c|c|c|c|c|c|c|}
\hline \multirow[t]{2}{*}{ Genotypes } & \multicolumn{4}{|c|}{ Fresh weight } & \multicolumn{4}{|c|}{ Dry weight } \\
\hline & SSI-T1 & SSI-T2 & STI-T1 & STI-T2 & SSI-T1 & SSI-T2 & STI-T1 & STI-T2 \\
\hline CIM-602 & -5.8453 & -4.03449 & 1.696203 & 1.936709 & -5.61152 & -9.75014 & 2.005714 & 3.012857 \\
\hline CIM-779 & -1.8046 & 0.219669 & 1.214936 & 0.948998 & 0.850737 & 1.243439 & 0.847528 & 0.7433 \\
\hline $6071 / 16$ & 4.872994 & 2.297404 & 0.419604 & 0.4666 & 2.625384 & 1.209773 & 0.529471 & 0.75025 \\
\hline IR-NIBGE-13 & 0.889258 & 1.836586 & 0.894085 & 0.57359 & 3.42651 & 3.13296 & 0.38589 & 0.35322 \\
\hline GH-HADI & 1.402846 & 0.665543 & 0.832915 & 0.845477 & 1.76483 & 2.34391 & 0.683702 & 0.516114 \\
\hline BS-2018 & 2.20583 & 1.108366 & 0.737275 & 0.742665 & 3.461762 & 1.908824 & 0.379572 & 0.605935 \\
\hline NIAB-512 & 2.575659 & 1.372777 & 0.693227 & 0.681275 & 0.403614 & 0.161721 & 0.927663 & 0.966614 \\
\hline NIAB-135 & 0.523862 & 1.425586 & 0.937606 & 0.669014 & 0.170252 & 1.807237 & 0.969487 & 0.626907 \\
\hline
\end{tabular}

SSI-T1, stress susceptibility index under $15 \mathrm{dS} / \mathrm{m}$ salt stress; SSI-T2, stress susceptibility index under $20 \mathrm{dS} / \mathrm{m}$ salt stress; STI-T1, stress tolerance index under $15 \mathrm{dS} / \mathrm{m}$ salt stress; STI-T2, stress tolerance index under 20 dS/m salt stress.

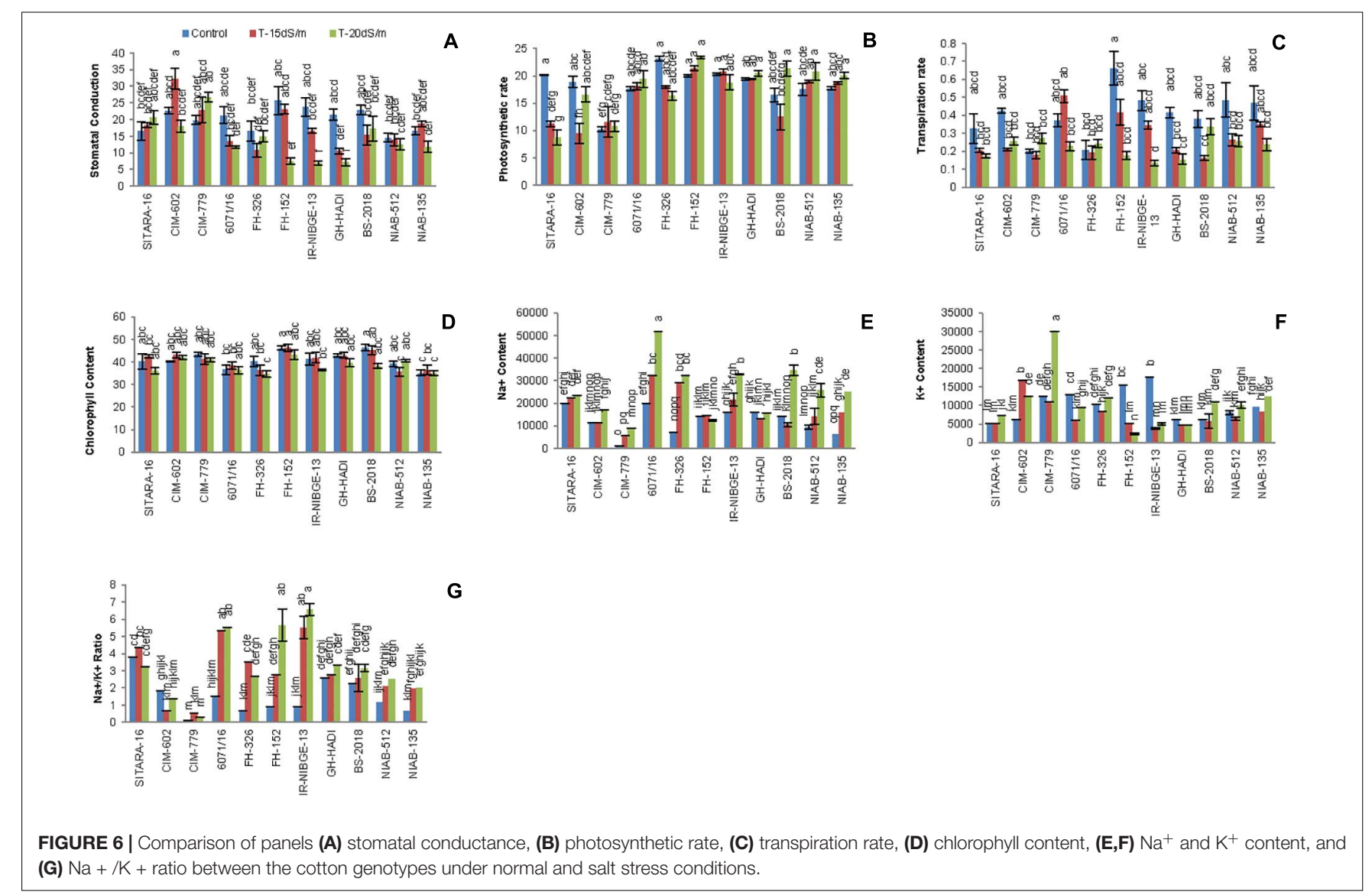

rate, which showed that they were least affected by salt stress (Table 6).

Chlorophyll content did not differ significantly in all the genotypes between salt-treated and non-treated plants before and after salt stress applied (chlorophyll content data before salt stress were not provided). This indicated that $\mathrm{NaCl}$ has no affect on the efficacy of light during photosynthesis.
Ionic Homeostasis ( $\mathrm{Na}^{+} / \mathrm{K}^{+}$Ratio)

$\mathrm{NaCl}$ treatment affected significantly ionic homeostasis in plant, i.e., $\mathrm{Na}^{+}, \mathrm{K}^{+}$, and $\mathrm{Na}^{+} / \mathrm{K}^{+}$ratio. $\mathrm{Na}^{+}$content was found to be increased in $\mathrm{NaCl}$-treated plants especially under the increased salt concentration, i.e., $20 \mathrm{dS} / \mathrm{m}$. Significant differences in $\mathrm{Na}^{+}$, $\mathrm{K}^{+}$, and $\mathrm{Na}^{+} / \mathrm{K}^{+}$ratio was observed among the genotypes. In IR-NIBGE-13 and 6071/16, $\mathrm{Na}^{+}$ion accumulated more in 
TABLE 6 | Stress susceptibility and tolerance indices for stomatal conductance and transpiration rate.

\begin{tabular}{|c|c|c|c|c|c|c|c|c|}
\hline \multirow[t]{2}{*}{ Genotypes } & \multicolumn{4}{|c|}{ Stomatal conductance } & \multicolumn{4}{|c|}{ Transpiration rate } \\
\hline & SSI-T1 & SSI-T2 & STI-T1 & STI-T2 & SSI-T1 & SSI-T2 & STI-T1 & STI-T2 \\
\hline SITARA-16 & -0.87014 & -0.7958 & 1.100472 & 1.239213 & 19.52062 & 0.938179 & 0.6298 & 0.529954 \\
\hline CIM-602 & -3.72031 & 0.687488 & 1.42957 & 0.793345 & 26.67516 & 0.786631 & 0.494118 & 0.605882 \\
\hline CIM-779 & -1.34662 & -1.16711 & 1.155489 & 1.350826 & 5.858886 & -0.68995 & 0.888889 & 1.345679 \\
\hline $6071 / 16$ & 3.137208 & 1.498992 & 0.637758 & 0.549411 & -19.1102 & 0.776939 & 1.362416 & 0.610738 \\
\hline $\mathrm{FH}-326$ & 3.029496 & 0.321093 & 0.650196 & 0.903481 & 3.451417 & -0.3508 & 0.934545 & 1.175758 \\
\hline $\mathrm{FH}-152$ & 0.860658 & 2.357692 & 0.900623 & 0.29129 & 19.55694 & 1.467706 & 0.629112 & 0.26465 \\
\hline IR-NIBGE-13 & 2.628489 & 2.36348 & 0.696498 & 0.28955 & 15.13596 & 1.440585 & 0.712953 & 0.278238 \\
\hline GH-HADI & 4.404499 & 2.215894 & 0.491429 & 0.333914 & 26.68264 & 1.251664 & 0.493976 & 0.372892 \\
\hline BS-2018 & 2.826926 & 0.814131 & 0.673586 & 0.755277 & 30.18097 & 0.223229 & 0.427632 & 0.888158 \\
\hline NIAB-512 & 0.367756 & 0.458233 & 0.957537 & 0.862257 & 24.19056 & 0.936235 & 0.541237 & 0.530928 \\
\hline NIAB-135 & -1.12746 & 0.94688 & 1.130184 & 0.715373 & 13.25299 & 0.981954 & 0.748663 & 0.508021 \\
\hline
\end{tabular}

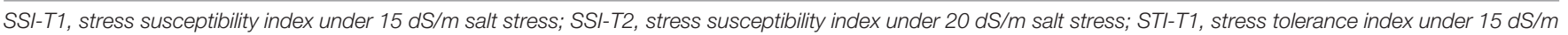
salt stress; STI-T2, stress tolerance index under $20 \mathrm{dS} / \mathrm{m}$ salt stress.

TABLE 7 | Stress susceptibility and tolerance indices for photosynthetic rate and chlorophyll content.

\begin{tabular}{|c|c|c|c|c|c|c|c|c|}
\hline \multirow[t]{2}{*}{ Genotypes } & \multicolumn{4}{|c|}{ Photosynthetic rate } & \multicolumn{4}{|c|}{ Chlorophyll content } \\
\hline & SSI-T1 & SSI-T2 & STI-T1 & STI-T2 & SSI-T1 & SSI-T2 & STI-T1 & STI-T2 \\
\hline SITARA-16 & 4.149185 & 23.85456 & 0.558551 & 0.435918 & -13.3327 & 1.624632 & 1.05528 & 0.896894 \\
\hline CIM-602 & 4.667792 & 5.125962 & 0.503374 & 0.878788 & -16.928 & -0.68509 & 1.070186 & 1.043478 \\
\hline CIM-779 & -1.13976 & -2.15814 & 1.121264 & 1.051033 & 12.20496 & 0.887972 & 0.949396 & 0.943646 \\
\hline $6071 / 16$ & -0.21364 & -4.15348 & 1.02273 & 1.098216 & -12.01 & 0.150476 & 1.049795 & 0.99045 \\
\hline $\mathrm{FH}-326$ & 2.091174 & 12.29666 & 0.777511 & 0.709224 & 23.31172 & 2.167315 & 0.903346 & 0.862454 \\
\hline $\mathrm{FH}-152$ & -0.65953 & -7.14621 & 1.07017 & 1.168984 & -0.78307 & 1.006127 & 1.003247 & 0.936147 \\
\hline IR-NIBGE-13 & -0.18764 & 3.173445 & 1.019964 & 0.924958 & -3.20611 & 1.856561 & 1.013293 & 0.882175 \\
\hline GH-HADI & -0.02664 & -2.25964 & 1.002834 & 1.053433 & -0.42166 & 1.175345 & 1.001748 & 0.925408 \\
\hline BS-2018 & 2.260667 & -12.4802 & 0.759478 & 1.295117 & 5.977687 & 2.767657 & 0.975216 & 0.824353 \\
\hline NIAB-512 & -0.77889 & -7.86551 & 1.08287 & 1.185993 & 22.1498 & -0.52255 & 0.908163 & 1.033163 \\
\hline NIAB-135 & -0.51155 & -5.5539 & 1.054426 & 1.131331 & -9.08521 & 0.033597 & 1.037669 & 0.997868 \\
\hline
\end{tabular}

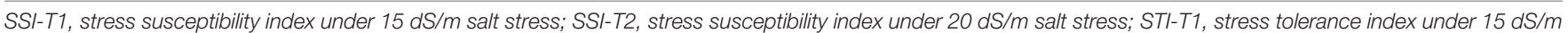
salt stress; STI-T2, stress tolerance index under $20 \mathrm{dS} / \mathrm{m}$ salt stress.

leaves as compared to $\mathrm{K}^{+}$ion and increase in $\mathrm{Na}^{+} / \mathrm{K}^{+}$ratio was observed. $\mathrm{Na}^{+}$content was maintained in SITARA-16, GHHADI, and FH-152.

$\mathrm{K}^{+}$concentration significantly decreased in IR-NIBGE-13 and $\mathrm{FH}-152$. The maximum value was recorded for $\mathrm{K}^{+}$ion in CIM779 under $20 \mathrm{dS} / \mathrm{m}$ salt stress condition. Moreover, $\mathrm{K}^{+}$content was maintained in NIAB-135, NIAB-512, GH-HADI, and FH$326 . \mathrm{Na}^{+} / \mathrm{K}^{+}$ratio significantly increased with the increase in salt concentration in IR-NIBGE-13, FH-152, FH-326, and 6071/16, whereas NIAB-512, NIAB-135, SITARA-16 CIM-602, and CIM779 maintained the $\mathrm{Na}^{+} / \mathrm{K}^{+}$ratio (Figure 6).

\section{Correlation Analysis Among Morphophysiological Traits}

Correlation (Pearson test) for morphophysiological traits under control and salt stress conditions was performed by using XLSTAT 2012.1.02 with 95\% confidence interval (Figure 7 and Tables 8-10). Root length (RL) under control was positively correlated with fresh weight (FW) under control but negatively correlated with FW and dry weight (DW) under $15 \mathrm{dS} / \mathrm{m}$ salt stress, which showed that salt stress had significant effects on plant growth and biomass, whereas shoot length (SL) under control was positively correlated with SL (under $15 \mathrm{dS} / \mathrm{m}$ ), FW (under control), and photosynthetic rate (PH-15 dS/m). SL under $15 \mathrm{dS} / \mathrm{m}$ was negatively correlated with stomatal conductance (Stcontrol) and chlorophyll content (CHL under $15 \mathrm{dS} / \mathrm{m}$ ). FW under control was positively correlated with DW (under control) but negatively correlated with St under salt stress. FW under $20 \mathrm{dS} / \mathrm{m}$ was negatively correlated with DW (under control), $\mathrm{Na}^{+}$(under $15 \mathrm{dS} / \mathrm{m}$ ), $\mathrm{Na}^{+} / \mathrm{K}^{+}$ratio (under $15 \mathrm{dS} / \mathrm{m}$ ), indicating that increase in $\mathrm{Na}^{+}$and $\mathrm{Na}^{+} / \mathrm{K}^{+}$ratio decreased the plant fresh weight under salt stress. $\mathrm{Na}^{+}$ion concentration under $15 \mathrm{dS} / \mathrm{m}$ was positively correlated with $\mathrm{Na}^{+}$ion under $20 \mathrm{dS} / \mathrm{m}, \mathrm{Na}^{+} / \mathrm{K}^{+}$ratio under $15 \mathrm{dS} / \mathrm{m}$ salt stress and $\mathrm{PH}$ under control condition. $\mathrm{Na}^{+}$under $20 \mathrm{dS} / \mathrm{m}$ salt condition was positively correlated with $\mathrm{Na}^{+} / \mathrm{K}^{+}$ratio 


\section{Correlationmap}

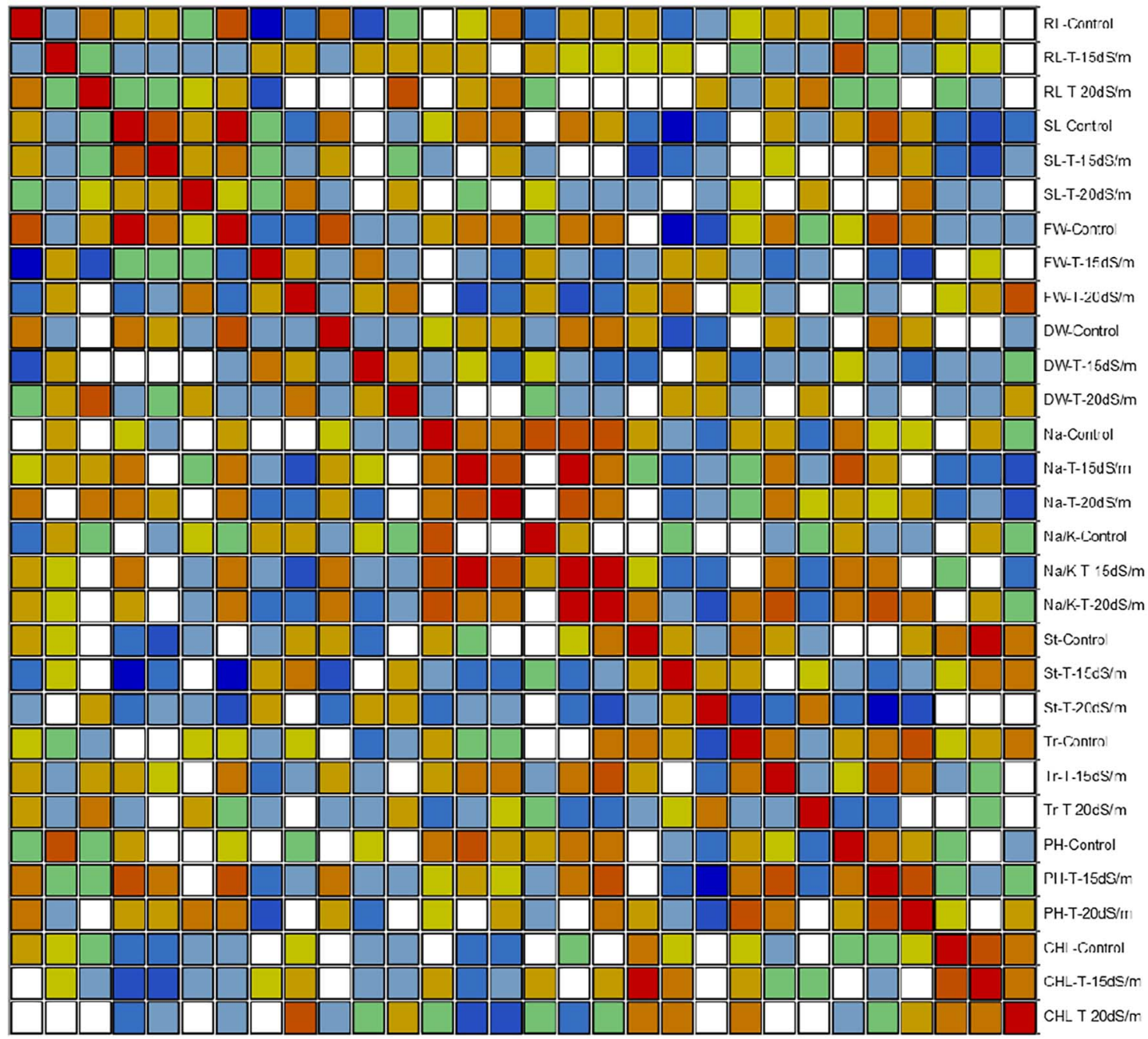

FIGURE 7 | Correlation matrix showing Pearson's correlation among morphophysiological traits in cotton genotypes under control and salt stress conditions. RL, root length; SL, shoot length; FW, fresh weight; DR, dry weight; Na, sodium content; Na/K, sodium to potassium ratio; St, stomatal conductance; Tr, transpiration rate; $\mathrm{PH}$, photosynthetic rate; $\mathrm{CHL}$, chlorophyll content.

under $15 \mathrm{dS} / \mathrm{m}$ salt stress condition. Similarly, $\mathrm{Na}^{+} / \mathrm{K}^{+}$ratio under $15 \mathrm{dS} / \mathrm{m}$ was positively correlated with $\mathrm{Na}^{+} / \mathrm{K}^{+}$ratio under $20 \mathrm{dS} / \mathrm{m}$ salt stress and also with $\mathrm{Na}^{+}$treatments. $\mathrm{Na}^{+} / \mathrm{K}^{+}$ratio under $20 \mathrm{dS} / \mathrm{m}$ was positively correlated with St-under $20 \mathrm{dS} / \mathrm{m}$ salt stress condition. Transpiration rate (Tr) under control and $\mathrm{PH}$ under $15 \mathrm{dS} / \mathrm{m}$ were positively correlated with $\mathrm{PH}$ under $20 \mathrm{dS} / \mathrm{m}$, and $\mathrm{CHL}$ under control was positively correlated with $\mathrm{CHL}$ under $15 \mathrm{dS} / \mathrm{m}$ salt stress conditions.

SSI-T1, stress susceptibility index under $15 \mathrm{dS} / \mathrm{m}$ salt stress; SSI-T2, stress susceptibility index under $20 \mathrm{dS} / \mathrm{m}$ salt stress; STI$\mathrm{T} 1$, stress tolerance index under $15 \mathrm{dS} / \mathrm{m}$ salt stress; STI-T2, stress tolerance index under $20 \mathrm{dS} / \mathrm{m}$ salt stress.

ANOVA for all morphological (Table 11) and physiological parameters explained in Table 12 indicated that shoot length, fresh and dry weights, and physiological parameters were highly significant except root length, which was non-significant under salt stress and non-stress conditions.

\section{Cluster Analysis}

Agglomerative hierarchical clustering of cotton genotypes was performed on the basis of morphophysiological traits under control and salt stress conditions (Figure 8). Cluster analysis grouped 11 genotypes into four clusters as shown in Table 13. Cluster I contained three genotypes followed by two, five, and one genotypes, respectively, in clusters II-IV.

\section{Principal Component Analysis}

The contribution of PC1 toward treatment was highest (47.06\%) followed by PC2, PC3, PC4, and PC5, which contributed as $24.26,10.39,9.52$, and $4.30 \%$, respectively, as shown in Table 14. The first five PCs had eigenvalues $>1$ and contributed 
TABLE 8 | Correlation matrix for morphological traits under control and salt stress conditions.

\begin{tabular}{|c|c|c|c|c|c|c|c|c|c|c|c|c|}
\hline Variables & RL-Control & $\mathrm{RL}-15 \mathrm{dS} / \mathrm{m}$ & $\mathrm{RL}-20 \mathrm{dS} / \mathrm{m}$ & SL-Control & $\mathrm{SL}-15 \mathrm{dS} / \mathrm{m}$ & $\mathrm{SL}-20 \mathrm{dS} / \mathrm{m}$ & FW-Control & $\mathrm{FW}-15 \mathrm{dS} / \mathrm{m}$ & $\mathrm{FW}-20 \mathrm{dS} / \mathrm{m}$ & DW-Control & $D W-15 d S / m$ & $\mathrm{DW}-20 \mathrm{dS} / \mathrm{m}$ \\
\hline RL-Control & 1 & & & & & & & & & & & \\
\hline $\mathrm{RL}-15 \mathrm{dS} / \mathrm{m}$ & -0.382 & 1 & & & & & & & & & & \\
\hline $\mathrm{RL}-20 \mathrm{dS} / \mathrm{m}$ & 0.430 & -0.148 & 1 & & & & & & & & & \\
\hline SL-Control & 0.342 & -0.273 & -0.118 & 1 & & & & & & & & \\
\hline $\mathrm{SL}-15 \mathrm{dS} / \mathrm{m}$ & 0.297 & -0.360 & -0.137 & 0.797 & 1 & & & & & & & \\
\hline $\mathrm{SL}-20 \mathrm{dS} / \mathrm{m}$ & -0.103 & -0.222 & 0.156 & 0.222 & 0.360 & 1 & & & & & & \\
\hline FW-Control & 0.671 & -0.400 & 0.215 & 0.851 & 0.586 & 0.173 & 1 & & & & & \\
\hline $\mathrm{FW}-15 \mathrm{dS} / \mathrm{m}$ & -0.850 & 0.228 & -0.684 & -0.199 & -0.119 & -0.126 & -0.569 & 1 & & & & \\
\hline $\mathrm{FW}-20 \mathrm{dS} / \mathrm{m}^{-1}$ & -0.471 & 0.211 & -0.097 & -0.470 & -0.238 & 0.499 & -0.432 & 0.337 & 1 & & & \\
\hline DW-Control & 0.510 & -0.256 & -0.017 & 0.599 & 0.261 & -0.219 & 0.776 & -0.225 & -0.302 & 1 & & \\
\hline DW-15 dS/m & -0.681 & 0.279 & -0.050 & -0.033 & -0.054 & 0.052 & -0.330 & 0.511 & 0.201 & -0.278 & 1 & \\
\hline DW-20 dS/m & -0.101 & 0.375 & 0.621 & -0.367 & -0.179 & 0.326 & -0.241 & -0.239 & 0.472 & -0.328 & 0.312 & 1 \\
\hline $\mathrm{Na}$-Control & -0.044 & 0.249 & 0.006 & 0.103 & -0.276 & -0.064 & 0.245 & -0.096 & -0.070 & 0.166 & -0.253 & -0.242 \\
\hline $\mathrm{Na}-15 \mathrm{dS} / \mathrm{m}$ & 0.146 & 0.265 & 0.356 & 0.456 & 0.084 & -0.161 & 0.452 & -0.348 & -0.615 & 0.228 & 0.111 & 0.086 \\
\hline $\mathrm{Na}-20 \mathrm{dS} / \mathrm{m}$ & 0.451 & -0.070 & 0.480 & 0.476 & 0.243 & 0.087 & 0.597 & -0.526 & -0.549 & 0.306 & -0.408 & 0.004 \\
\hline $\mathrm{Na} / \mathrm{K}$-Control & -0.467 & 0.296 & -0.137 & -0.099 & -0.322 & 0.148 & -0.178 & 0.350 & 0.237 & -0.223 & 0.134 & -0.200 \\
\hline $\mathrm{Na} / \mathrm{K}-15 \mathrm{dS} / \mathrm{m}$ & 0.241 & 0.197 & 0.010 & 0.480 & 0.035 & -0.389 & 0.529 & -0.227 & -0.641 & 0.478 & -0.243 & -0.371 \\
\hline $\mathrm{Na} / \mathrm{K}-20 \mathrm{dS} / \mathrm{m}$ & 0.399 & 0.116 & -0.070 & 0.310 & -0.052 & -0.334 & 0.514 & -0.415 & -0.439 & 0.465 & -0.512 & -0.361 \\
\hline St-Control & 0.216 & 0.124 & -0.019 & -0.444 & -0.611 & -0.239 & -0.059 & -0.231 & 0.249 & 0.243 & -0.554 & 0.002 \\
\hline St-15 dS/m & -0.474 & 0.111 & -0.060 & -0.851 & -0.527 & -0.041 & -0.800 & 0.306 & 0.523 & -0.626 & 0.074 & 0.355 \\
\hline St-20 dS/m & -0.286 & -0.062 & 0.256 & -0.562 & -0.323 & -0.200 & -0.630 & 0.343 & 0.078 & -0.456 & 0.312 & 0.204 \\
\hline Tr-Control & 0.103 & -0.139 & -0.346 & 0.048 & 0.099 & 0.200 & 0.148 & -0.205 & 0.152 & -0.053 & -0.422 & -0.257 \\
\hline $\operatorname{Tr}-15 \mathrm{dS} / \mathrm{m}$ & 0.348 & -0.346 & 0.253 & 0.293 & 0.117 & -0.043 & 0.530 & -0.512 & -0.366 & 0.321 & -0.288 & -0.070 \\
\hline $\operatorname{Tr}-20 \mathrm{dS} / \mathrm{m}$ & 0.284 & -0.337 & 0.501 & -0.252 & 0.062 & 0.383 & -0.165 & -0.296 & 0.083 & -0.360 & -0.243 & 0.315 \\
\hline $\mathrm{PH}$-Control & -0.159 & 0.673 & -0.184 & 0.275 & -0.012 & 0.066 & 0.119 & -0.095 & -0.152 & -0.089 & 0.144 & 0.060 \\
\hline $\mathrm{PH}-15 \mathrm{dS} / \mathrm{m}$ & 0.486 & -0.149 & -0.185 & 0.712 & 0.507 & -0.004 & 0.751 & -0.434 & -0.383 & 0.578 & -0.211 & -0.296 \\
\hline $\mathrm{PH}-20 \mathrm{dS} / \mathrm{m}$ & 0.568 & -0.238 & 0.022 & 0.360 & 0.334 & 0.475 & 0.567 & -0.635 & 0.058 & 0.269 & -0.597 & -0.042 \\
\hline CHL-Control & 0.264 & 0.154 & -0.159 & -0.470 & -0.504 & -0.351 & -0.255 & -0.100 & 0.168 & 0.024 & -0.380 & -0.203 \\
\hline $\mathrm{CHL}-15 \mathrm{dS} / \mathrm{m}$ & -0.095 & 0.184 & -0.224 & -0.633 & -0.776 & -0.272 & -0.394 & 0.110 & 0.347 & -0.066 & -0.341 & -0.203 \\
\hline $\mathrm{CHL}-20 \mathrm{dSm}$ & 0.027 & -0.021 & 0.013 & -0.600 & -0.285 & 0.042 & -0.365 & -0.070 & 0.640 & -0.267 & -0.116 & 0.262 \\
\hline
\end{tabular}

Values in bold are different from 0 with a significance level alpha $=0.05 . R L$, root Length; SL, shoot length; FW, fresh weight; DW, dry weight; Na+/K+, sodium to potassium ration; St, stomatal conductance; Tr; transpiration rate; $\mathrm{PH}$, photosynthetic rate; $\mathrm{CHL}$, chlorophyll content. 
TABLE 9 | Correlation matrix for physiological traits under control and salt stress conditions.

\begin{tabular}{|c|c|c|c|c|c|c|c|c|c|c|c|c|c|c|c|c|c|c|}
\hline Variables & $\begin{array}{c}\mathrm{Na}- \\
\text { Control }\end{array}$ & $\begin{array}{l}\mathrm{Na}-15 \\
\mathrm{dS} / \mathrm{m}\end{array}$ & $\begin{array}{l}\mathrm{Na}-20 \\
\mathrm{dS} / \mathrm{m}\end{array}$ & $\begin{array}{l}\mathrm{Na} / \mathrm{K}- \\
\text { Control }\end{array}$ & $\begin{array}{c}\mathrm{Na} / \mathrm{K}- \\
15 \\
\mathrm{dS} / \mathrm{m}\end{array}$ & $\begin{array}{c}\mathrm{Na} / \mathrm{K}- \\
20 \\
\mathrm{dS} / \mathrm{m}\end{array}$ & $\begin{array}{c}\text { St- } \\
\text { Control }\end{array}$ & $\begin{array}{l}\text { St-15 } \\
\text { dS/m }\end{array}$ & $\begin{array}{l}\text { St-20 } \\
\text { dS/m }\end{array}$ & $\begin{array}{c}\text { Tr- } \\
\text { Control }\end{array}$ & $\begin{array}{l}\mathrm{Tr}-15 \\
\mathrm{dS} / \mathrm{m}\end{array}$ & $\begin{array}{l}\mathrm{Tr}-20 \\
\mathrm{dS} / \mathrm{m}\end{array}$ & $\begin{array}{l}\text { PH- } \\
\text { Control }\end{array}$ & $\begin{array}{l}\mathrm{PH}-15 \\
\mathrm{dS} / \mathrm{m}\end{array}$ & $\begin{array}{l}\mathrm{PH}-20 \\
\mathrm{dS} / \mathrm{m}\end{array}$ & $\begin{array}{l}\text { CHL- } \\
\text { Control }\end{array}$ & $\begin{array}{c}\text { CHL- } \\
15 \\
\text { dS } / m\end{array}$ & $\begin{array}{l}\text { CHL- } \\
20 \\
\text { dS/m }\end{array}$ \\
\hline Na-Control & 1 & & & & & & & & & & & & & & & & & \\
\hline $\mathrm{Na}-15 \mathrm{dS} / \mathrm{m}$ & 0.469 & 1 & & & & & & & & & & & & & & & & \\
\hline $\mathrm{Na}-20 \mathrm{dS} / \mathrm{m}$ & 0.451 & 0.755 & 1 & & & & & & & & & & & & & & & \\
\hline $\mathrm{Na} / \mathrm{K}$-Control & 0.723 & 0.098 & 0.084 & 1 & & & & & & & & & & & & & & \\
\hline $\mathrm{Na} / \mathrm{K}-15 \mathrm{dS} / \mathrm{m}$ & 0.731 & 0.812 & 0.699 & 0.264 & 1 & & & & & & & & & & & & & \\
\hline $\mathrm{Na} / \mathrm{K}-20 \mathrm{dS} / \mathrm{m}$ & 0.720 & 0.541 & 0.479 & 0.089 & 0.837 & 1 & & & & & & & & & & & & \\
\hline St-Control & 0.346 & -0.195 & -0.087 & -0.030 & 0.109 & 0.502 & 1 & & & & & & & & & & & \\
\hline St-15 dS/m & -0.220 & -0.482 & -0.508 & -0.107 & -0.548 & -0.310 & 0.353 & 1 & & & & & & & & & & \\
\hline St-20 dS/m & -0.441 & -0.312 & -0.241 & 0.048 & -0.484 & -0.740 & -0.313 & 0.373 & 1 & & & & & & & & & \\
\hline Tr-Control & 0.333 & -0.152 & -0.122 & -0.012 & 0.085 & 0.539 & 0.435 & 0.211 & -0.710 & 1 & & & & & & & & \\
\hline $\operatorname{Tr}-15 \mathrm{dS} / \mathrm{m}$ & 0.362 & 0.494 & 0.442 & -0.270 & 0.500 & 0.684 & 0.273 & -0.042 & -0.570 & 0.540 & 1 & & & & & & & \\
\hline $\operatorname{Tr}-\mathrm{T}-20 \mathrm{dS} / \mathrm{m}^{-1}$ & -0.484 & -0.327 & 0.132 & -0.188 & -0.547 & -0.594 & -0.204 & 0.135 & 0.575 & -0.362 & -0.360 & 1 & & & & & & \\
\hline $\mathrm{PH}$-Control & 0.476 & 0.614 & 0.268 & 0.293 & 0.533 & 0.498 & -0.005 & -0.276 & -0.591 & 0.261 & 0.145 & -0.495 & 1 & & & & & \\
\hline $\mathrm{PH}-\mathrm{T}-15 \mathrm{dS} / \mathrm{m}^{-1}$ & 0.138 & 0.347 & 0.198 & -0.363 & 0.451 & 0.646 & 0.086 & -0.529 & -0.871 & 0.533 & 0.601 & -0.520 & 0.410 & 1 & & & & \\
\hline PH-T-20 dS/m & 0.144 & -0.028 & 0.217 & -0.240 & 0.072 & 0.458 & 0.373 & -0.219 & -0.782 & 0.709 & 0.448 & 0.019 & 0.244 & 0.670 & 1 & & & \\
\hline CHL-Control & 0.028 & -0.509 & -0.429 & 0.087 & -0.187 & 0.093 & 0.595 & 0.117 & 0.074 & 0.121 & -0.376 & 0.076 & -0.137 & -0.112 & 0.121 & 1 & & \\
\hline CHL-15 dS/m & 0.380 & -0.420 & -0.369 & 0.370 & -0.053 & 0.244 & 0.808 & 0.404 & -0.002 & 0.312 & -0.132 & -0.149 & -0.055 & -0.246 & 0.057 & 0.798 & 1 & \\
\hline $\mathrm{CHL}-20 \mathrm{dS} / \mathrm{m}$ & -0.158 & -0.696 & -0.662 & -0.104 & -0.596 & -0.164 & 0.452 & 0.566 & 0.057 & 0.412 & -0.094 & 0.081 & -0.347 & -0.131 & 0.200 & 0.566 & 0.521 & 1 \\
\hline
\end{tabular}

Values in bold are different from $\mathrm{O}$ with a significance level alpha $=0.05 ; \mathrm{Na}+$, Sodium concentration; $\mathrm{Na}+\mathrm{IK}+$, Sodium to Potassium ratio; St, Stomatal Conductance; Tr, Transpiration rate; PH, Photosynthetic rate; CHL, Chlorophyll content. 
TABLE 10 | Stress susceptibility and tolerance Indices of $\mathrm{Na}^{+}$and $\mathrm{Na}^{+} / \mathrm{K}^{+}$ratio.

\begin{tabular}{|c|c|c|c|c|c|c|c|c|}
\hline \multirow[t]{2}{*}{ Genotypes } & \multicolumn{4}{|c|}{$\mathrm{Na}^{+}$content } & \multicolumn{4}{|c|}{$\mathrm{Na}+/ \mathrm{K}+$ ratio } \\
\hline & SSI-T1 & SSI-T2 & STI-T1 & STI-T2 & SSI-T1 & SSI-T2 & STI-T1 & STI-T2 \\
\hline SITARA-16 & 0.341495 & 0.172787 & 1.139445 & 1.184181 & 0.147589 & -0.1269 & 1.140432 & 0.845925 \\
\hline CIM-602 & -0.02141 & 0.469071 & 0.991259 & 1.5 & -0.66263 & -0.2059 & 0.369501 & 0.75 \\
\hline CIM-779 & 8.847853 & 5.7499 & 4.612903 & 7.129032 & 4.489623 & 1.627089 & 5.271889 & 2.975596 \\
\hline $6071 / 16$ & 1.546711 & 1.516409 & 1.631579 & 2.616397 & 2.622059 & 2.172452 & 3.494896 & 3.637771 \\
\hline $\mathrm{FH}-326$ & 7.524984 & 3.292024 & 4.072727 & 4.509091 & 4.299419 & 2.405675 & 5.090909 & 3.920949 \\
\hline $\mathrm{FH}-152$ & 0.080237 & -0.11057 & 1.032764 & 0.88214 & 2.204925 & 4.358455 & 3.097993 & 6.291996 \\
\hline IR-NIBGE-13 & 0.820384 & 0.967852 & 1.334993 & 2.031669 & 5.311725 & 5.100416 & 6.054122 & 7.192879 \\
\hline GH-HADI & -0.47396 & -0.03025 & 0.806464 & 0.967757 & 0.079062 & 0.239124 & 1.075228 & 1.290343 \\
\hline BS-2018 & -0.61577 & 1.383826 & 0.748558 & 2.475071 & 0.150801 & 0.327585 & 1.143488 & 1.397751 \\
\hline NIAB-512 & 1.253252 & 1.644566 & 1.511749 & 2.753004 & 0.808035 & 0.938074 & 1.768847 & 2.139 \\
\hline NIAB-135 & 3.738854 & 2.768775 & 2.526712 & 3.95134 & 2.073148 & 1.716422 & 2.972606 & 3.084063 \\
\hline
\end{tabular}

TABLE 11 | ANOVA for morphological parameters.

\begin{tabular}{lcccc}
\hline & Root length & Shoot length & Fresh weight & Dry weight \\
\hline $\mathrm{R}^{2}$ & 0.329 & 0.523 & 0.536 & 0.601 \\
$\mathrm{~F}$ & 1.518 & 3.395 & 3.569 & 4.654 \\
$\mathrm{Pr}>\mathrm{F}$ & 0.061 & $<0.0001$ & $<0.0001$ & $<0.0001$ \\
\hline
\end{tabular}

95.55\% of the cumulative variability (Figure 9). On the basis of SSI and STI for morphophysiological traits, PC1 was mainly positively affected by SSI for $\mathrm{FW}, \mathrm{DW}, \mathrm{Na}^{+}, \mathrm{Na}^{+} / \mathrm{K}^{+}$ratio, ST and STI for $\mathrm{Na}^{+} / \mathrm{K}^{+}$ratio, $\mathrm{Na}+$ and $\mathrm{PH}$, and vice versa. PC2 was positively affected by SSI and STI for $\mathrm{Na}^{+}$ and $\mathrm{Na}^{+} / \mathrm{K}^{+}$ratio but negatively affected by FW-SSI (under $15 \mathrm{dS} / \mathrm{m}$ ), FW-STI (under $20 \mathrm{dS} / \mathrm{m}$ ), DW-STI (under 20 $\mathrm{dS} / \mathrm{m}$ ), PH-SSI and STI (under 15 and $20 \mathrm{dS} / \mathrm{m}$ ), and ST-SSI under both stresses.

In biplot diagram, a vector was illustrated toward each genotypes and parameters from the origin to understand interrelationship between the genotypes along with traits (morphophysiological) and treatment's SSI and STI (0, 15, $20 \mathrm{dS} / \mathrm{m}$ salt stress). Moreover PC1 and PC2 accounting for 47.06 and $24.26 \%$ were responsible for $71.33 \%$ variations among genotypes as shown in Figure 10. The biplot analysis indicated that CIM-779, CIM-602, and SITARA-16 were largely dispersed and away from the origin, which showed high variability for morphophysiological traits under salinity. The sensitive genotypes IR-NIBGE-13 and 6071/16 were very close to the traits FW-SSI and DW-SSI under $15 \mathrm{dS} / \mathrm{m}$ salt stress. The moderately tolerant genotypes NIAB-512, FH-152, BS2018, and GH-HADI were close to the traits PH-STI (under $20 \mathrm{dS} / \mathrm{m}$ ) and ST-SSI under both stress conditions. NIAB135 was close to the traits $\mathrm{Na}^{+} / \mathrm{K}^{+}$SSI and STI (under 15 $\mathrm{dS} / \mathrm{m})$. Genotypes positioned closer to the ideal genotypes like NIAB-135, FH-326, NIAB-512, GH-HADI, and FH-152 are preferable for biochemical selection along with poor performing genotypes, which are closed to each other but farthest away from tolerant genotypes, i.e., IR-NIBGE-13 and 6071/16 selected as sensitive genotypes for more biochemical analysis and confirmation.

\section{Biochemical Results Lycopene}

Salt stress caused a marked decrease in lycopene content among the genotypes with the exception of 6071/16. In FH-152, lycopene content was significantly reduced under both stress conditions. However, lycopene content was maintained in the NIAB-135, NIAB-512, and FH-326 (Figure 11A).

\section{Chlorophyll a}

Chlorophyll a content was generally less affected by salt stress in most of the genotypes like NIAB-512, NIAB-132, and 6071/16. In IR-NIBGE-13, chlorophyll content increased under $15 \mathrm{dS} / \mathrm{m}$ but decreased with the increase of salt concentration. In contrast, chlorophyll content was significantly reduced in $\mathrm{FH}$ 236 under $15 \mathrm{dS} / \mathrm{m}$ but increased under $20 \mathrm{dS} / \mathrm{m}$ salt stress condition (Figure 11B).

\section{Chlorophyll b}

Chlorophyll b content was non-significant in all the genotypes. The decrease in chlorophyll b content was seen in GH-HADI, IRNIBGE-13, and NIAB-512, but in 6071/16, chlorophyll content was increased under salt stress. In NIAB-135, chlorophyll b content was reduced under $15 \mathrm{dS} / \mathrm{m}$ but increased under 20 $\mathrm{dS} / \mathrm{m}$ (Figure 11C).

\section{Total Carotene}

In general, total carotene content decreased in all the genotypes, except IR-NIBGE-13 in which the total carotene was more increased under $15 \mathrm{dS} / \mathrm{m}$ stress condition as compared to $20 \mathrm{dS} / \mathrm{m}$. Carotene content was significantly decreased in FH-326 under $15 \mathrm{dS} / \mathrm{m}$ salt stress condition but maintained under $20 \mathrm{dS} / \mathrm{m}$. However, in NIAB-512, FH-152, and $6017 / 16$, carotene content showed least significant variations between stress and non-stress conditions. In NIAB-135, a significant decrease in carotene content under severe salt stress condition $(20 \mathrm{dS} / \mathrm{m})$ was observed. A significant decrease in 
TABLE 12 | ANOVA for physiological parameters.

\begin{tabular}{|c|c|c|c|c|c|c|c|}
\hline & $\begin{array}{l}\text { Stomatal conduction } \\
\qquad\left(\mathrm{mmol} \mathrm{m} \mathrm{m}^{-2} \mathrm{~s}^{-1}\right)\end{array}$ & $\begin{array}{l}\text { Transpiration rate (mmol } \\
\left.\qquad \mathrm{m}^{-2} \mathrm{~s}^{-1}\right)\end{array}$ & $\begin{array}{l}\text { Photosynthetic rate } \\
\qquad\left(\mu \mathrm{mol} \mathrm{m}{ }^{-2} \mathrm{~s}^{-1}\right)\end{array}$ & SPAD & $\mathrm{Na}^{+}$ & $\mathbf{K}^{+}$ & $\mathrm{Na}^{+} / \mathrm{K}^{+}$ \\
\hline $\mathrm{R}^{2}$ & 0.646 & 0.576 & 0.743 & 0.583 & 0.961 & 0.974 & 0.932 \\
\hline $\mathrm{F}$ & 5.658 & 4.208 & 8.954 & 4.323 & 75.241 & 117.646 & 42.148 \\
\hline $\mathrm{Pr}>\mathrm{F}$ & $<0.0001$ & $<0.0001$ & $<0.0001$ & $<0.0001$ & $<0.0001$ & $<0.0001$ & $<0.0001$ \\
\hline
\end{tabular}

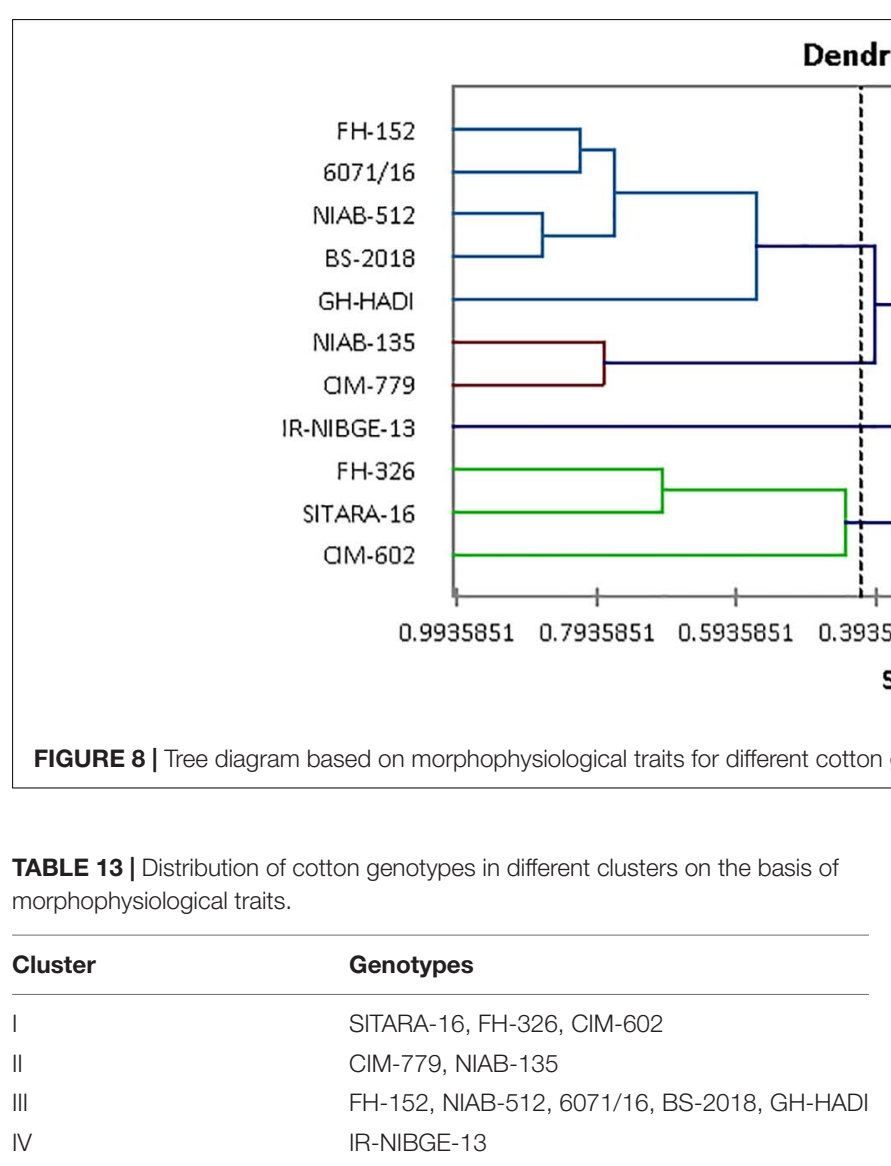

carotene content was observed in GH-HADI under stress conditions (Figure 11D).

\section{Total Chlorophyll}

Salt stress had least significant difference in total chlorophyll content among the genotypes. Total chlorophyll content was non-significant in IR-NIBGE-13 and FH-152. However, a significant increase in NIAB-512 and 6017/16 under stress was observed. Salt-treated plants of GH-HADI had reduced chlorophyll content compared with that in control plants (Figure 11E).

\section{Total Phenolic Contents}

A significant increase in total phenolic content (TPC) in 6071/16, NIAB-512, and NIAB-135 was observed under salt stress conditions. However, the decrease in TPC content was observed in FH-152 under stress conditions. The salt-treated plants of FH-326 and GH-HADI were not significantly affected by the treatment and successfully maintained TPC. In IR-NIBGE13, TPC content was significantly decreased under $15 \mathrm{dS} / \mathrm{m}$, but with the increase in salt concentration, plants maintained TPC (Figure 11F).

\section{Tannins}

Generally, tannins were maintained in all the genotypes under control and stress conditions. Most genotypes showed nonsignificant increase for tannins except NIAB-512, which showed significant increase under salt stress conditions. In NIAB-135, tannins were significantly increased under $15 \mathrm{dS} / \mathrm{m}$ salt stress condition (Figure 11G).

\section{Total Flavonoids}

A general trend was seen in all the genotypes for total flavonoids. Mostly, the non-significant results were found under stress and non-stress conditions for total flavonoids. However, tolerant genotypes NIAB-135 showed significant increase in total flavonoids under $20 \mathrm{dS} / \mathrm{m}$ salt stress condition. The highest values recorded for total flavonoids were for NIAB-135 under stress and for FH-326 under control condition and lowest value for total flavonoids in FH-152 under control and 15 $\mathrm{dS} / \mathrm{m}$ (Figure 11H).

\section{Ascorbic Acid}

For ascorbic acid (AsA) content, a significant increase in NIAB-512 and NIAB-135 under salt stress conditions was observed. In 6071/16, ascorbic acid was significantly increased under $20 \mathrm{dS} / \mathrm{m}$ salt stress condition. Ascorbic acid content was 
TABLE 14 | Principal component analysis for morphophysiological traits under control and salt stress conditions in different cotton genotypes.

\begin{tabular}{|c|c|c|c|c|c|c|c|c|c|c|}
\hline & PC1 & PC2 & РC3 & PC4 & PC5 & PC6 & PC7 & PC8 & PC9 & PC10 \\
\hline Eigenvalue & 11.295 & 5.825 & 2.495 & 2.286 & 1.032 & 0.514 & 0.379 & 0.108 & 0.064 & 0.003 \\
\hline Variability (\%) & 47.063 & 24.269 & 10.397 & 9.523 & 4.301 & 2.140 & 1.578 & 0.450 & 0.265 & 0.013 \\
\hline Cumulative\% & 47.063 & 71.332 & 81.730 & 91.253 & 95.554 & 97.694 & 99.271 & 99.722 & 99.987 & 100.000 \\
\hline
\end{tabular}
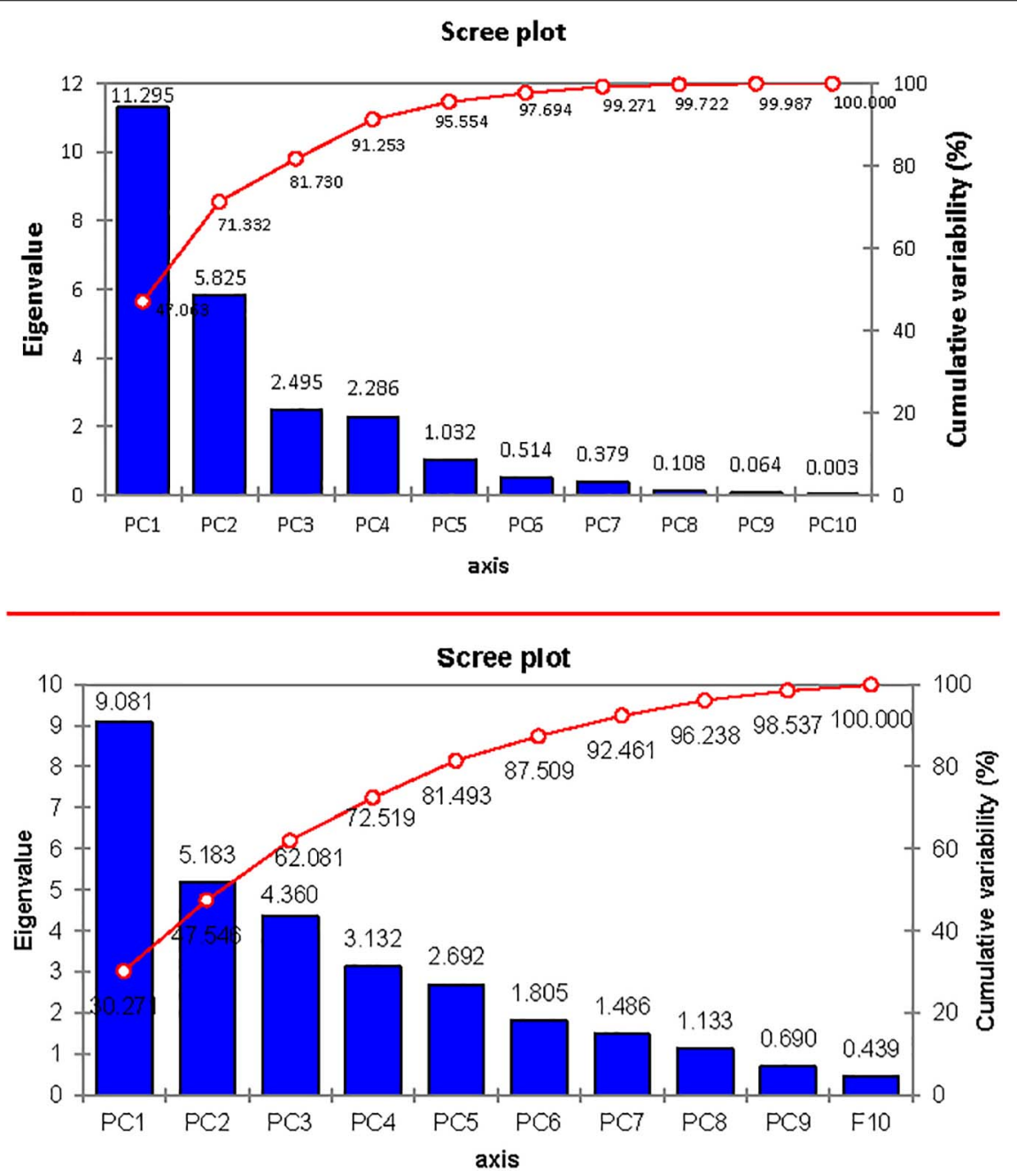

FIGURE 9 | Scree plot between eigenvalues and principal components (PCs) under control and salt stress conditions.

maintained in FH-326 and IR-NIBGE-13. Ascorbic acid content was significantly decreased in GH-HADI under $15 \mathrm{dS} / \mathrm{m}$ salt stress condition (Figure 11I).

\section{Total Soluble Protein}

The genotypes did not show alleviatory effects of salt stress for total soluble protein. Mostly, the genotypes showed nonsignificant results for total soluble protein under stress and non-stress conditions. The maximum value was recorded for total soluble protein in FH-326 genotype under $20 \mathrm{dS} / \mathrm{m}$, and minimum value was observed for 6071/16 under control condition (Figure 11J).

\section{Reducing Sugar}

Salt stress had no significant affect on reducing sugars in all the genotypes, as the general trend was observed among the genotypes. under stress and non-stress conditions (Figure 11K).

\section{Amylase}

The amylase content was significantly increased in 6071/16, FH-326, NIAB-512, and NIAB-135 under stress and non-stress conditions. In GH-HADI, a significant increase in amylase content under $15 \mathrm{dS} / \mathrm{m}$ was observed. However, amylase content was significantly reduced under $20 \mathrm{dS} / \mathrm{m}$ salt stress condition in 


\section{Biplot (axes PC1 and PC2: $71.33 \%$ )}

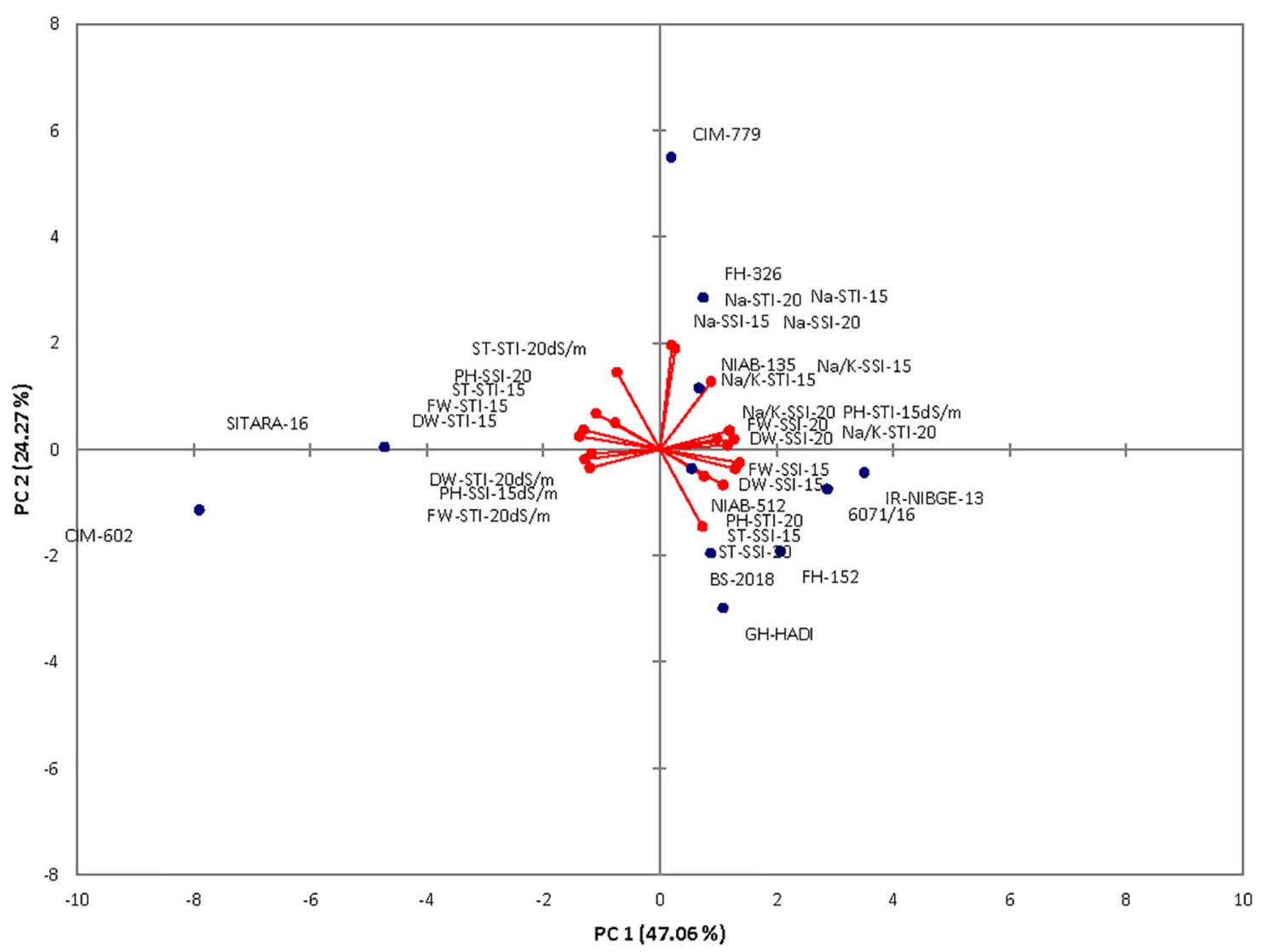

FIGURE 10 | Biplot illustration of all the genotypes under control and salt stress conditions.

GH-HADI. Amylase content was significantly decreased in FH152, but in IR-NIBGE-13, a significant increase in amylase under $20 \mathrm{dS} / \mathrm{m}$ stress condition was observed (Figure 11L).

\section{Catalase Activity}

For catalase activity in cotton leaves under salt stress, significant variations were found among the genotypes. The CAT activity was significantly increased in NIAB-135 under salt stress conditions. In contrast, CAT activity was reduced in 6071/16 and $\mathrm{FH}-152$ under salt stress conditions. In NIAB-512 and GH-HADI, CAT activity was significantly increased under $20 \mathrm{dS} / \mathrm{m}$ compared with $15 \mathrm{dS} / \mathrm{m}$ salt stress condition in which it was significantly decreased. CAT activity was found to be increased under more salt concentrations of $20 \mathrm{dS} / \mathrm{m}$ among the genotypes in IR-NIBGE13 and maintained in FH-326 under stress and non-stress conditions (Figure 12A).

\section{Peroxidases Activity}

For POD activity, a significant variation was found among cotton genotypes. In GH-HADI, FH-152, and NIAB-135, a significant increase in POD activity was observed under salt stress conditions. Similarly, a significant decrease in POD activity in some genotypes like NIAB-512 was observed. The highest value for POD activity was observed in NIAB-135 under $15 \mathrm{dS} / \mathrm{m}$ salt stress condition and lowest values in 6071/16 and FH-152 under control condition. In 6071/16, a significant increase in POD activity was observed under $20 \mathrm{dS} / \mathrm{m}$ salt condition. FH326 exhibited significant increase under $20 \mathrm{dS} / \mathrm{m}$ and maintained under $15 \mathrm{dS} / \mathrm{m}$ stress condition. POD activity was maintained in IR-NIBGE-13 under stress and non-stress conditions (Figure 12B).

\section{Ascorbate Peroxidase Activity}

Ascorbate Peroxidase activity prevents the oxidative damage caused by $\mathrm{H}_{2} \mathrm{O}_{2}$ (Kohli et al., 2019). Plants under stress trigger the APX activity in the cell. Under the severe stress conditions, salt-treated plants of FH-152 and NIAB-135 had undergone oxidative stress; as a result, more activity of APX was seen under $20 \mathrm{dS} / \mathrm{m}$. In contrast, APX activity was more increased in IR-NIBGE-13 under $15 \mathrm{dS} / \mathrm{m}$ compared to that in control and $20 \mathrm{dS} / \mathrm{m}$. The genotypes 6071/16, NIAB-512, and FH-326 showed non-significant results for APX activity under salt stress conditions. GH-HADI showed significant decrease in APX activity under stress conditions (Figure 12C). 

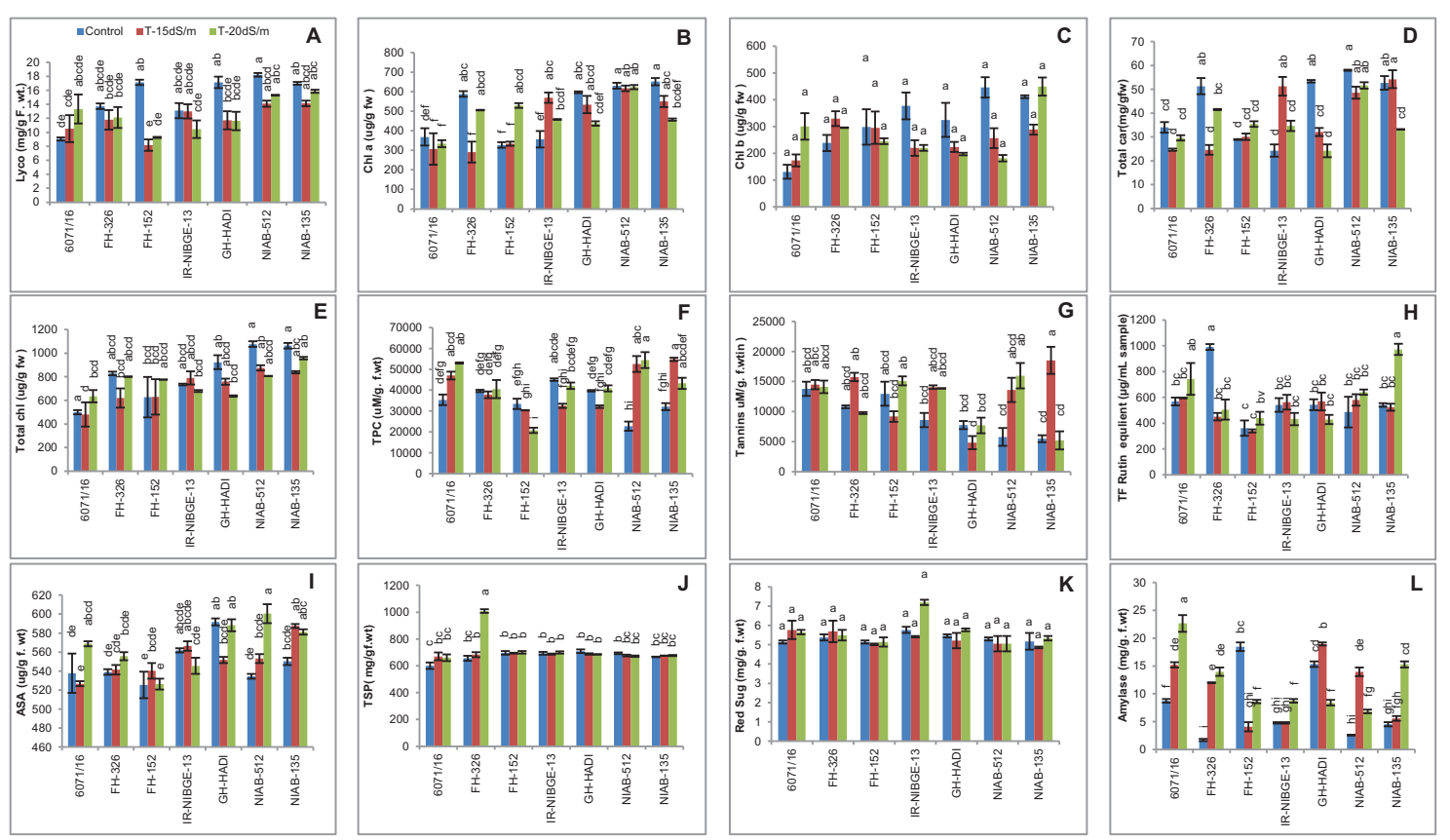

FIGURE 11 | Comparison of panels (A) lycopene, (B) chlorophyll a, (C) chlorophyll b, (D) total carotenoids, (E) total chlorophyll, (F) total phenolic content, (G) tannins, (H) total flavonoids, (I) ascorbic acid, ( $\mathbf{J})$ total soluble proteins, (K) reducing sugars, and (L) amylase in cotton genotypes under stress and non-stress conditions.
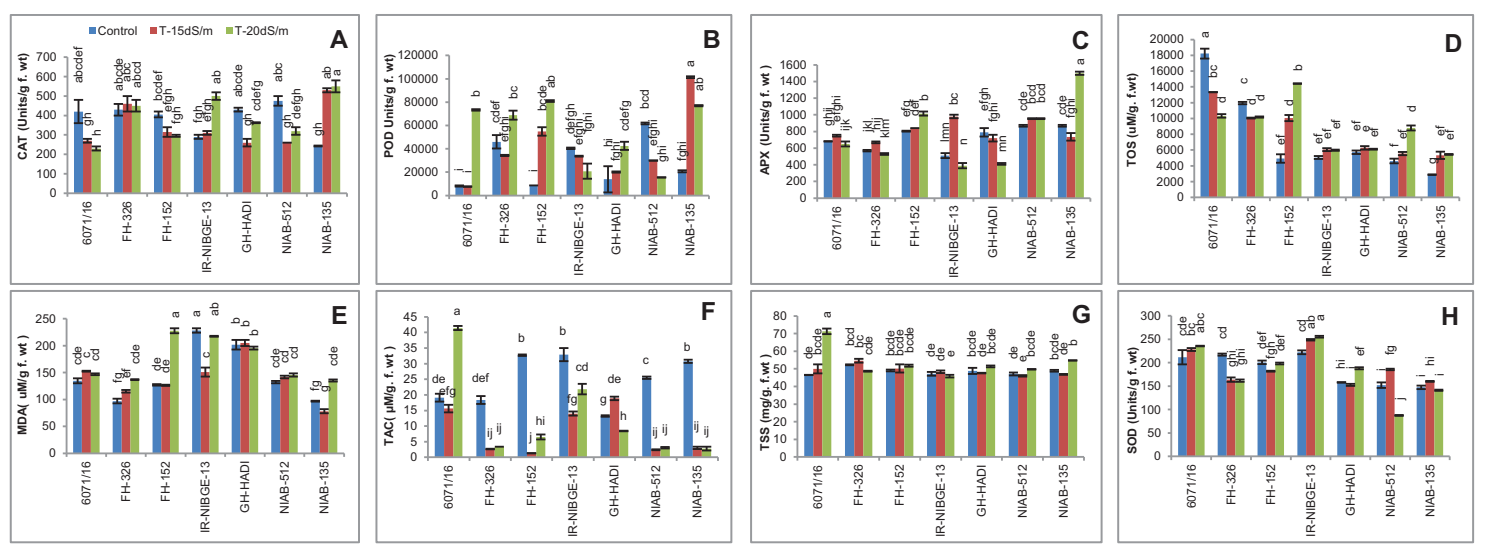

FIGURE 12 | Comparison of panels (A) catalase, (B) peroxidase, (C) ascorbate peroxidase, (D) total oxidant status, (E) malondialdehyde, (F) total antioxidant capacity, (G) total soluble sugar, and (H) superoxide dismutase in cotton genotypes under stress and non-stress conditions.

\section{Total Oxidant Status}

For TOS activity, a significant increase was observed in FH-152 and NIAB-512 under stress conditions except in 6071/16. The rest of the genotypes showed non-significant results for TOS under salt stress and non-stress conditions. In FH-152, TOS activity was significantly increased under stress (Figure 12D).

\section{Malondialdehyde Content}

The lipid peroxidation under salt stress was evaluated in terms of MDA content. In our results, salt stress caused low effect on lipid peroxidation, as most of the genotypes showed nonsignificant results. However, in FH-326, a significant increase in MDA content under stress conditions was observed. MDA content was significantly increased in NIAB-135 and IR-NIBGE13 under $20 \mathrm{dS} / \mathrm{m}$ but significantly decreased under $15 \mathrm{dS} / \mathrm{m}$ salt stress condition. The maximum MDA content was recorded in FH-152 under $20 \mathrm{dS} / \mathrm{m}$ salt stress (Figure 12E).

\section{Total Antioxidant Capacity}

The tolerant genotypes, i.e.,FH-152, NIAB-512, and NIAB-135, had shown least activity of TAC under stress conditions as compared to control. However, in sensitive genotypes (i.e., 6071/16), TAC activity increased. The highest value for TAC was observed in 6071/16 under $20 \mathrm{dS} / \mathrm{m}$ and the lowest 


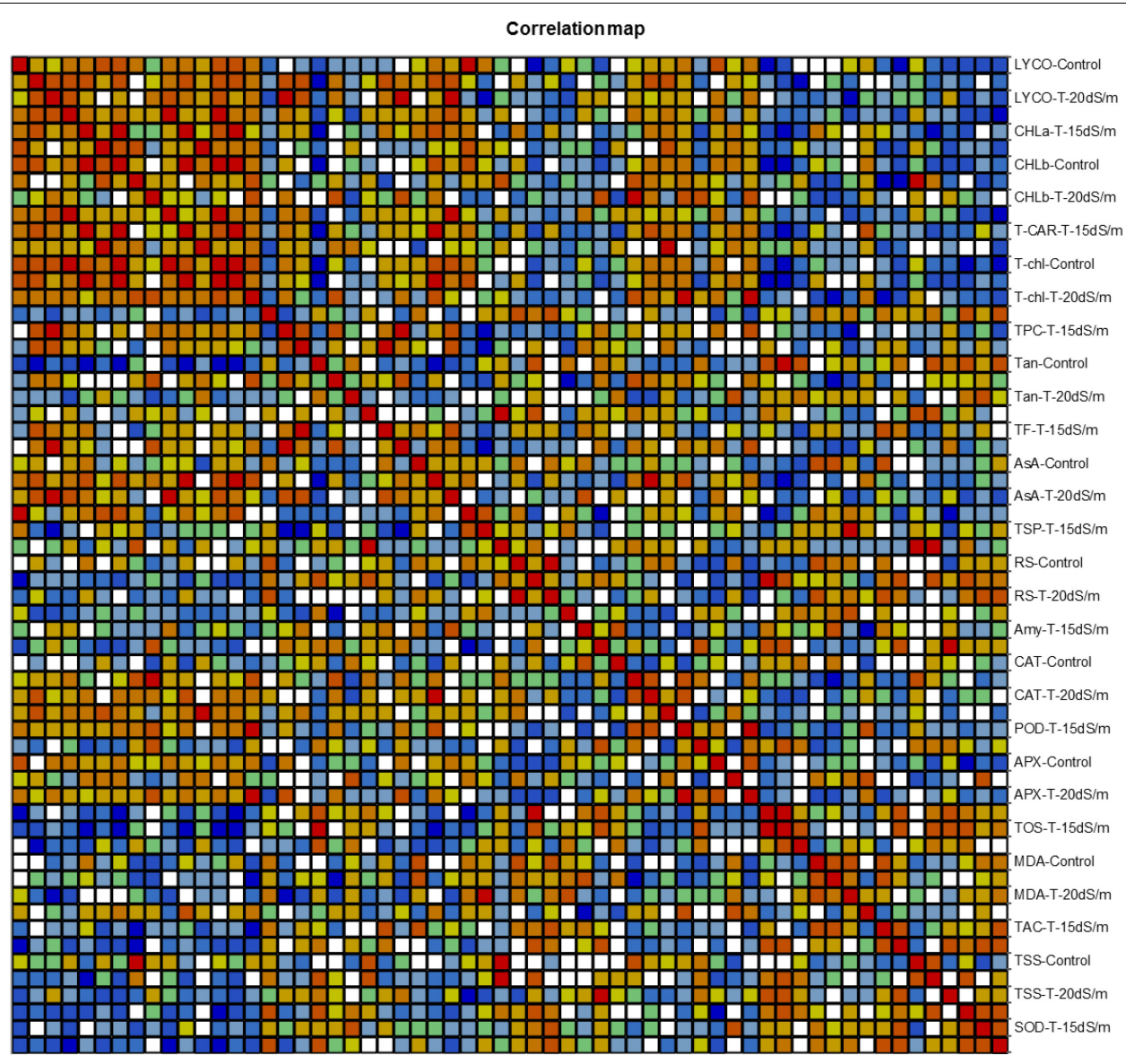

FIGURE 13 | Correlation matrix showing Pearson's correlation among biochemical traits in cotton genotypes under stress and non-stress conditions. LYCO, lycopene content; CHL-a, chlorophyll a; CHL-b, chlorophyll b; T-CAR, total carotenoids; T-chl, total chlorophyll; TPC, total phenolic content; Tan, tannins; TF, total flavonoids; AsA, ascorbic acid; TSP, total soluble protein; RS, reducing sugar; Amy, amylase; CAT, catalase; POD, peroxidase; APX, ascorbate peroxidase; TOS, total oxidant status; MDA, malondialdehyde; TAC, total antioxidant status; TSS, total soluble sugar; SOD, superoxide dismutase Cluster Analysis.

value in NIAB-135, NIAB-512, and FH-326 under stress conditions (Figure 12F).

\section{Total Soluble Sugar}

In general, a non-significant result for total soluble sugar was observed in all the genotypes except 6071/16, in which a significant increase in total soluble sugar was recorded under 20 $\mathrm{dS} / \mathrm{m}$ salt stress condition (Figure 12G).

\section{Superoxide Dismutase}

The overproduction of reactive oxygen species (ROS) especially $\mathrm{O}_{2}{ }^{-}$is mainly regulated by SOD (Kohli et al., 2019). More ROS generation leads to more activity of SOD enzyme. Similarly, in our results, more activity of SOD was seen under severe $(20 \mathrm{dS} / \mathrm{m})$ salt stress condition compared to control. However, the tolerant genotypes showed maintained activity of SOD under salt-treated and non-salt-treated plants. In contrast, SOD activity was found to be significantly increased in IR-NIBGE-13 under salt stress. In NIAB-512, SOD content was significantly increased under 15 $\mathrm{dS} / \mathrm{m}$ salt stress, but under severe salt stress, SOD activity was reduced. In FH-326, SOD activity was significantly decreased under stress conditions. SOD content was significantly increased in GH-HADI under $20 \mathrm{dS} / \mathrm{m}$ salt stress but maintained under 15 $\mathrm{dS} / \mathrm{m}$ salt stress condition. Similarly, it was maintained in FH152 and NIAB-135 under salt stress and non-stress conditions (Figure 12H).

\section{Correlation Analysis Among Biochemical Traits}

Correlation (Pearson test) for biochemical traits under control and salt stress conditions was performed by using XLSTAT 2012.1.02 with 95\% confidence interval (Figure 13). Among all the genotypes under control and salt stress conditions, positive correlation with biochemical traits was expressed in bold form and negative correlation in bold form with negative sign as well. Thus, on this basis, significant correlation among genotypes under control, $15 \mathrm{dS} / \mathrm{m}$, and $20 \mathrm{dS} / \mathrm{m}$ with biochemical traits related to stress tolerance was easily identified. In normal condition, LYCO was positively correlated with TSP and negatively correlated with TOS. Chlorophyll a (CHL-a) was positively correlated with total carotene (T-CAR) and negatively 
correlated with tannins (Tan). CHL-b was positively correlated with LYCO and total chlorophyll (T-CHL) and negatively with Tan and TOS. The negative correlation between TSP with TOS, amylase Amy with POD and Tan with SOD was observed under control conditions (Table 15).

Similarly, in $15 \mathrm{dS} / \mathrm{m}$ salt stress condition, LYCO was positively correlated with CHL-a, T-CAR, and T-Chl. However, CHL-a was negatively correlated with TOS and TSS. AsA was positively correlated with POD and negatively correlated with TOS, which showed that POD and AsA were involved in scavenging ROS. CAT was positively correlated with POD and negatively correlated with MDA, indicating that low activity of antioxidative enzymes like CAT and POD caused more oxidative damage in the form of lipid peroxidation. MDA (an indicator of oxidative damage) was positively correlated with TAC under 15 $\mathrm{dS} / \mathrm{m}$ (Table 16). This correlation directly showed that with the increase in MDA, a relative amount of TAC also increased to cope with ROS under $15 \mathrm{dS} / \mathrm{m}$ salt stress.

LYCO under $20 \mathrm{dS} / \mathrm{m}$ was positively correlated with TF and AsA and negatively correlated with MDA. CHL-a and CHL-b were positively correlated with T-CAR and TF under severe salt stress $(20 \mathrm{dS} / \mathrm{m})$. Amy was positively correlated with TSS, hence showed that sugar has some protective role under salt stress. SOD was negatively correlated with T-Chl content, explaining more SOD activity due to more ROS production in cell, which had effect on other parameters in the cell like T-Chl content (Table 17).

Agglomerative hierarchical clustering of cotton genotypes was performed on the basis of biochemical traits under control and salt stress conditions (Figure 14). Cluster analysis grouped seven genotypes into four clusters as shown in Table 18. Cluster I contained one genotype followed by two, two, and two genotypes, respectively, in clusters II, III, and IV.

\section{Principal Component Analysis}

The contributed cumulative variability of PC1 toward treatment was highest $(30.978 \%)$ followed by PC2, PC3, PC4, PC5, and PC6, which contributed as 50.909, 67.289, 79.434, 90.604, and $100.000 \%$, respectively (Figure 15). Thus, the highly contributed PCs are shown in Table 19. The PC1 had mostly positive loading for biochemical traits except for TPC, Tan, TF, RS, Amy, CAT, TOS, MDA, and SOD (under control); TSP, RS, Amy, TOS,MDA, TAC, TSS, and SOD (under $15 \mathrm{dS} / \mathrm{m}$ ); and Tan, TSP, RS, Amy, TOS, MDA, TAC, TSS, and SOD (under $20 \mathrm{dS} / \mathrm{m})$. The PC2 was mostly negative affected except for CHL-a, T-CAR, Tan, TF, CAT, APX, TOS, TSS, and SOD (under control); CHL-b, TPC, Tan, RS, Amy, CAT, POD, APX, TOS, and TSS (under $15 \mathrm{dS} / \mathrm{m}$ ); and LYCO, CHL-b, T-CAR, T-chl, TPC,TF, AsA, TSP, Amy, POD, APX, TOS, TAC, and TSS (under $20 \mathrm{dS} / \mathrm{m}$ ). In biplot diagram, a vector was illustrated toward each genotypes and parameters from the origin to understand interrelationship between the genotypes along with traits (biochemical) and treatments (0, 15, and 20 $\mathrm{dS} / \mathrm{m}$ salt stress conditions). Moreover, PC1 and PC2 were responsible for $50.91 \%$ variations among genotypes as shown in Figure 16.

\section{DISCUSSION}

Seed germination, seedling emergence, and plant growth are affected by salinity stress in cotton (Zhong and Läuchli, 1993), although cotton is considered as the second most salt-tolerant crop, barely with salinity threshold at $7.7 \mathrm{dS} / \mathrm{m}$, but increase in salt concentration adversely affects cotton yield (Higbie et al., 2010). Salt stress causes water deficiency in roots and imposes drought to the plant. Many physiological (stomatal conductance and photosynthetic activity) and metabolic changes occur under salt stress. Initially, it causes osmotic stress, which interrupts the physiological functioning followed by ion toxicity and oxidative stress (Higbie et al., 2010). However, plants developed different physiological and biochemical defense mechanisms in order to maintain their cellular and metabolic activities, in which most important mechanism is $\mathrm{Na}^{+}$compartmentalization (Peng et al., 2016). The maintenance of ion homeostasis especially $\mathrm{Na}^{+}$sequestration is key mechanism to survive under salinity along with activation of antioxidant enzymes (Gupta and Huang, 2014).

In our experiment, initial screening for salt tolerance under $0,7.5$, and $15 \mathrm{dS} / \mathrm{m}$ was done by seed germination and radical elongation (growth chamber) test, and then, selected sensitive and tolerant genotypes were transferred into sand pots (glass house) for further screening at seedling stage under 15 and 20 $\mathrm{dS} / \mathrm{m}$ salt stress conditions. With the help of these two screening procedures, it showed that genotypes possessed different genetic diversity for salt tolerance. Thus, the evidence of these differences was based on plant fresh and dry weights, photosynthetic rate, $\mathrm{Na}^{+} / \mathrm{K}^{+}$ratio, and biochemical and stress markers (SOD, POD, APX, CAT, MDA, TOS, amylase, and AsA).

Results of the current study showed that in the first experiment, salt stress negatively affected seed germination parameters, i.e., growth index and growth energy, which is highly retarded by salt. As the cotton germination is very a critical stage, some genotypes performed well even at this stage of severe salt stress, i.e., NIAB-512, NIAB-135, and FH-152. Thus, the salt tolerance ability of plants is genotypic dependent. Plants that showed tolerance under germination stage performed relatively better under increased salt concentrations at their early growth stages.

Salt stress reduces the dry weight and biomass accumulation (Higbie et al., 2010). A significant decrease in fresh and dry weights was also observed in our experiment. $\mathrm{NaCl}$ treatment significantly reduced plant biomass in two genotypes IR-NIBGE13 and BS-2018. A similar trend was also noted in other genotypes. However, NIAB-135, NIAB-512, and GH-HADI had the least difference in fresh weight between control and $\mathrm{NaCl}-$ treated plants. Plant fresh weight was significantly reduced in $6071 / 16$. Thus, a reduction in plant biomass was found to be reliable method for the determination of salt stress tolerance in cotton, as the reduction in sensitive genotypes was more than tolerant genotypes. The root and shoot lengths showed non-significant change. On the basis of STI, CIM-602, GHHADI, and FH-326 found to be tolerant genotypes for root length under stress conditions. Similarly, CIM-602, NIAB-512, NIAB-135, CIM-779, and FH-326 showed more STI values for 
TABLE 15 | Correlation matrix for biochemical traits under normal conditions.

Variables LYCO- CHLa- CHLb- T- T-chl- TPC- Tan- TF- AsA- TSP- RS- Amy- CAT- POD- APX- TOS- MDA- TAC- TSS- SODControl Control Control CAR- Control Control Control Control Control Control Control Control Control Control Control Control Control Control Control Control Control

LYCO-Control $\mathbf{1}$

CHLa-Control $0.532 \quad 1$

$\begin{array}{llll}\text { CHLb-Control } & \mathbf{0 . 7 8 9} & 0.470 & \mathbf{1}\end{array}$

$\begin{array}{lllll}\text { T-CAR-Control } & 0.514 & \mathbf{0 . 9 6 7} & 0.347 & 1\end{array}$

$\begin{array}{llllll}\text { T-chl-Control } & 0.746 & \mathbf{0 . 8 9 8} & \mathbf{0 . 8 1 0} & \mathbf{0 . 8 1 5} & \mathbf{1}\end{array}$

$\begin{array}{lllllll}\text { TPC-Control } & -0.472 & -0.389 & -0.350 & -0.504 & -0.432 & \mathbf{1}\end{array}$

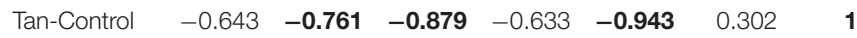

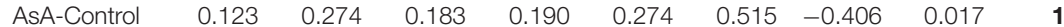

$\begin{array}{lllllllllll}\text { TSP-Control } & \mathbf{0 . 8 1 9} & 0.204 & 0.745 & 0.146 & 0.506 & -0.007 & -0.521 & -0.337 & 0.389 & \mathbf{1}\end{array}$

$\begin{array}{llllllllllll}\text { RS-Control } & -0.069 & -0.082 & 0.300 & -0.223 & 0.095 & 0.650 & -0.287 & 0.190 & 0.575 & 0.442 & \mathbf{1}\end{array}$

$\begin{array}{llllllllllll}\text { Amy-Control } & 0.183 & -0.447 & -0.236 & -0.345 & -0.414 & 0.117 & 0.431 & -0.572 & 0.178 & 0.275 & -0.251\end{array}$

$\begin{array}{llllllllllllll}\text { CAT-Control } & 0.035 & 0.055 & -0.319 & 0.287 & -0.122 & -0.343 & 0.311 & 0.129 & -0.184 & -0.011 & -0.226 & 0.179 & \mathbf{1}\end{array}$

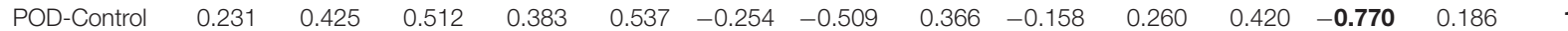

$\begin{array}{llllllllllllllll}\text { APX-Control } & 0.683 & 0.450 & 0.415 & 0.528 & 0.505 & -\mathbf{0 . 8 0 0} & -0.402 & -0.555 & -0.089 & 0.241 & -0.650 & 0.294 & 0.120 & -0.176 & \mathbf{1}\end{array}$

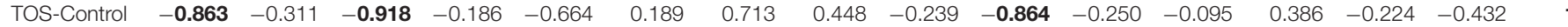

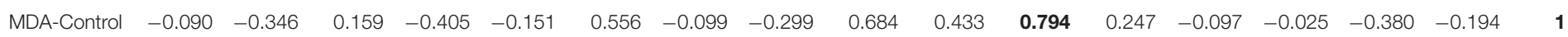

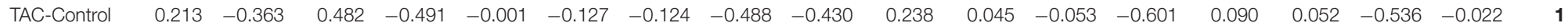

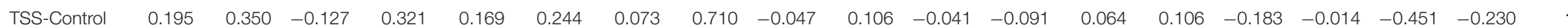

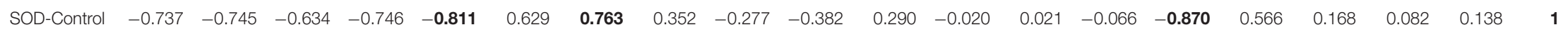

Values in bold are different from 0 with a significance level alpha $=0.05$. 
TABLE 16 | Correlation matrix for biochemical traits under $15 \mathrm{dS} / \mathrm{m}$ salt stress condition.

\begin{tabular}{|c|c|c|c|c|c|c|c|c|c|c|c|c|c|c|c|c|c|c|c|c|}
\hline Variables & $\begin{array}{c}\text { LYCO- } \\
15 \\
\text { dS/m }\end{array}$ & $\begin{array}{c}\text { CHLa- } \\
15 \\
\text { dS/m }\end{array}$ & $\begin{array}{l}\text { CHLb- } \\
15 \\
\text { dS/m }\end{array}$ & $\begin{array}{c}\text { T- } \\
\text { CAR- } \\
15 \\
\text { dS/m }\end{array}$ & $\begin{array}{l}\text { T-chl- } \\
15 \\
\text { dS/m }\end{array}$ & $\begin{array}{l}\text { TPC- } \\
15 \\
\mathrm{dS} / \mathrm{m}\end{array}$ & $\begin{array}{l}\text { Tan-15 } \\
\text { dS/m }\end{array}$ & $\begin{array}{l}\text { TF-15 } \\
\mathrm{dS} / \mathrm{m}\end{array}$ & $\begin{array}{c}\text { AsA- } \\
15 \\
d S / m\end{array}$ & $\begin{array}{c}\text { TSP- } \\
15 \\
\text { dS/m }\end{array}$ & $\begin{array}{l}\text { RS-15 } \\
\text { dS/m }\end{array}$ & $\begin{array}{l}\text { Amy- } \\
15 \\
\text { dS/m }\end{array}$ & $\begin{array}{l}\text { CAT-15 } \\
\text { dS/m }\end{array}$ & $\begin{array}{l}\text { POD- } \\
15 \\
\text { dS/m }\end{array}$ & $\begin{array}{l}\text { APX- } \\
15 \\
\text { dS/m }\end{array}$ & $\begin{array}{l}\text { TOS- } \\
15 \\
\text { dS/m }\end{array}$ & $\begin{array}{l}\text { MDA- } \\
15 \\
\text { dS/m }\end{array}$ & $\begin{array}{l}\text { TAC- } \\
15 \\
\text { dS/m }\end{array}$ & $\begin{array}{c}\text { TSS- } \\
15 \\
\text { dS/m }\end{array}$ & $\begin{array}{c}\text { SOD- } \\
15 \\
\text { dS/m }\end{array}$ \\
\hline LYCO-15 dS/m & 1 & & & & & & & & & & & & & & & & & & & \\
\hline CHLa-15 dS/m & 0.760 & 1 & & & & & & & & & & & & & & & & & & \\
\hline CHLb-15 dS/m & 0.002 & -0.176 & 1 & & & & & & & & & & & & & & & & & \\
\hline T-CAR-15 dS/m & 0.756 & 0.866 & 0.014 & 1 & & & & & & & & & & & & & & & & \\
\hline T-chl-15 dS/m & 0.756 & 0.928 & 0.203 & 0.866 & 1 & & & & & & & & & & & & & & & \\
\hline TPC-15 dS/m & 0.618 & 0.282 & -0.029 & 0.417 & 0.270 & 1 & & & & & & & & & & & & & & \\
\hline Tan-15 dS/m & 0.492 & -0.028 & 0.231 & 0.375 & 0.059 & 0.672 & 1 & & & & & & & & & & & & & \\
\hline TF-15 dS/m & 0.647 & 0.527 & -0.722 & 0.324 & 0.251 & 0.452 & 0.129 & 1 & & & & & & & & & & & & \\
\hline AsA-15 dS/m & 0.706 & 0.725 & 0.236 & 0.879 & 0.810 & 0.319 & 0.359 & 0.162 & 1 & & & & & & & & & & & \\
\hline TSP-15 dS/m & -0.484 & -0.038 & 0.338 & -0.126 & 0.091 & -0.871 & -0.647 & -0.645 & -0.028 & 1 & & & & & & & & & & \\
\hline RS-15 dS/m & -0.231 & -0.595 & -0.335 & -0.629 & -0.719 & -0.210 & 0.113 & 0.228 & -0.650 & -0.258 & 1 & & & & & & & & & \\
\hline Amy-15 dS/m & 0.083 & -0.011 & -0.399 & -0.442 & -0.162 & 0.103 & -0.405 & 0.546 & -0.451 & -0.317 & 0.374 & 1 & & & & & & & & \\
\hline CAT-15 dS/m & 0.297 & -0.121 & 0.677 & 0.219 & 0.136 & 0.318 & 0.666 & -0.304 & 0.548 & -0.166 & -0.176 & -0.451 & 1 & & & & & & & \\
\hline POD-15 dS/m & 0.262 & 0.227 & 0.582 & 0.554 & 0.446 & 0.330 & 0.443 & -0.374 & 0.766 & 0.033 & -0.710 & -0.674 & 0.782 & 1 & & & & & & \\
\hline APX-15 dS/m & 0.221 & 0.559 & -0.250 & 0.590 & 0.462 & -0.029 & -0.002 & 0.163 & 0.184 & 0.167 & -0.265 & -0.364 & -0.474 & -0.097 & 1 & & & & & \\
\hline TOS-15 dS/m & -0.728 & -0.922 & -0.175 & -0.837 & -0.984 & -0.157 & 0.018 & -0.254 & -0.838 & -0.169 & 0.691 & 0.148 & -0.149 & -0.439 & -0.392 & 1 & & & & \\
\hline MDA-15 dS/m & -0.200 & 0.142 & -0.631 & -0.315 & -0.098 & -0.502 & -0.812 & 0.395 & -0.419 & 0.270 & 0.277 & 0.662 & -0.829 & -0.788 & 0.112 & 0.023 & 1 & & & \\
\hline TAC-15 dS/m & -0.041 & 0.114 & -0.834 & -0.173 & -0.203 & -0.315 & -0.445 & 0.620 & -0.176 & -0.047 & 0.426 & 0.504 & -0.526 & -0.593 & -0.055 & 0.088 & 0.790 & 1 & & \\
\hline TSS-15 dS/m & -0.500 & -0.860 & 0.408 & -0.737 & -0.701 & -0.398 & 0.119 & -0.511 & -0.550 & 0.170 & 0.670 & -0.022 & 0.285 & -0.221 & -0.509 & 0.675 & -0.167 & -0.178 & 1 & \\
\hline SOD-15 dS/m & -0.056 & -0.004 & -0.626 & 0.133 & -0.241 & -0.102 & 0.213 & 0.320 & -0.183 & -0.156 & 0.445 & -0.257 & -0.412 & -0.392 & 0.609 & 0.259 & 0.151 & 0.369 & -0.050 & 1 \\
\hline
\end{tabular}

Values in bold are different from 0 with a significance level alpha $=0.05$. 
TABLE 17 | Correlation matrix for biochemical traits under $20 \mathrm{dS} / \mathrm{m}$ salt stress condition.

\begin{tabular}{|c|c|c|c|c|c|c|c|c|c|c|c|c|c|c|c|c|c|c|c|}
\hline VariablesLYCO-20 dS/m & $\begin{array}{c}\text { CHLa- } \\
20 \\
\mathrm{dS} / \mathrm{m}\end{array}$ & $\begin{array}{c}\text { CHLb- } \\
20 \\
\text { dS/m }\end{array}$ & $\begin{array}{c}\text { T- } \\
\text { CAR- } \\
20 \\
\text { dS/m }\end{array}$ & $\begin{array}{l}\text { T-chl- } \\
20 \\
\text { dS/m }\end{array}$ & $\begin{array}{l}\text { TPC- } \\
20 \\
\text { dS/m }\end{array}$ & $\begin{array}{l}\text { Tan-20 } \\
\text { dS/m }\end{array}$ & $\begin{array}{l}\text { TF-20 } \\
\text { dS/m }\end{array}$ & $\begin{array}{c}\text { AsA- } \\
20 \\
\text { dS/m }\end{array}$ & $\begin{array}{l}\text { TSP- } \\
20 \\
\text { dS/m }\end{array}$ & $\begin{array}{l}\text { RS-20 } \\
\text { dS/m }\end{array}$ & $\begin{array}{l}\text { Amy- } \\
20 \\
\text { dS/m }\end{array}$ & $\begin{array}{l}\text { CAT-20 } \\
\text { dS/m }\end{array}$ & $\begin{array}{l}\text { POD- } \\
20 \\
d S / m\end{array}$ & $\begin{array}{l}\text { APX- } \\
20 \\
d S / m\end{array}$ & $\begin{array}{l}\text { TOS- } \\
20 \\
\mathrm{dS} / \mathrm{m}\end{array}$ & $\begin{array}{l}\text { MDA- } \\
20 \\
\text { dS/m }\end{array}$ & $\begin{array}{l}\text { TAC- } \\
20 \\
\mathrm{dS} / \mathrm{m}\end{array}$ & $\begin{array}{l}\text { TSS- } \\
20 \\
d S / m\end{array}$ & $\begin{array}{c}\text { SOD- } \\
20 \\
d S / m\end{array}$ \\
\hline
\end{tabular}

LYCO-20 dS/m1

CHLa-20 dS/m0.093

CHLb-20 dS/m0.461

T-CAR-20 dS/m0.329

T-chl-20 dS/m0.532

TPC-20 dS $/ \mathrm{m} 0.735$

Tan-20 dS/m-0.315

TF-20 dS/m0.848

AsA-20 dS/m0.808

TSP-20 dS/m-0.171

RS-20 dS/m-0.405

Amy-20 dS/m0.311

CAT-20 dS $/ \mathrm{m0} .173$

POD-20 dS/m-0.074

APX-20 dS $/ \mathrm{m} 0.555$

TOS-20 dS/m-0.437

MDA-20 dS/m-0.856

TAC-20 dS/m-0.133

TSS-20 dS $/ \mathrm{m} 0.272$

1

$-0.360 \quad 1$

$\begin{array}{lll}0.826 & -0.209 & 1\end{array}$

$\begin{array}{llll}0.471 & 0.650 & 0.451 & \mathbf{1}\end{array}$

$\begin{array}{lllll}-0.149 & 0.003 & 0.235 & -0.106 & 1\end{array}$

$\begin{array}{llllll}0.294 & -0.629 & 0.465 & -0.381 & 0.025 & \mathbf{1}\end{array}$

$\begin{array}{lllllll}-0.209 & \mathbf{0 . 7 9 9} & 0.044 & 0.600 & 0.462 & -0.382 & \mathbf{1}\end{array}$

$\begin{array}{llllllll}0.109 & -0.009 & 0.154 & 0.118 & \mathbf{0 . 7 6 3} & -0.301 & 0.454 & 1\end{array}$

$\begin{array}{lllllllll}0.167 & 0.091 & 0.270 & 0.170 & -0.159 & -0.197 & -0.269 & -0.263 & 1\end{array}$

$\begin{array}{llllllllll}-0.378 & -0.203 & -0.326 & -0.484 & 0.072 & 0.052 & -0.362 & -0.287 & -0.056 & \mathbf{1}\end{array}$

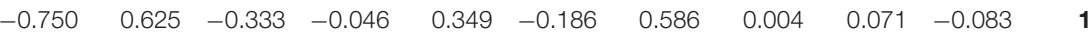

$\begin{array}{llllllllllll}0.084 & 0.478 & 0.006 & 0.541 & -0.058 & -0.630 & 0.206 & -0.006 & 0.277 & 0.390 & -0.162 & \mathbf{1}\end{array}$

$\begin{array}{lllllllllllll}-0.403 & 0.683 & -0.375 & 0.286 & -0.450 & -0.338 & 0.340 & -0.402 & 0.223 & -0.444 & 0.610 & -0.089 & 1\end{array}$

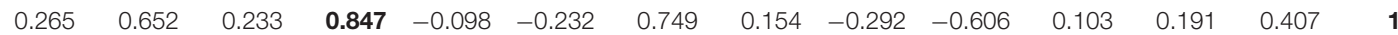

$\begin{array}{lllllllllllllll}0.198 & -0.183 & 0.232 & -0.065 & -0.498 & 0.584 & -0.285 & -0.572 & 0.207 & -0.481 & 0.072 & -0.652 & 0.467 & 0.060 & 1\end{array}$

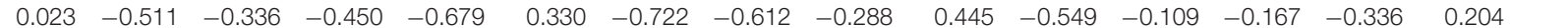

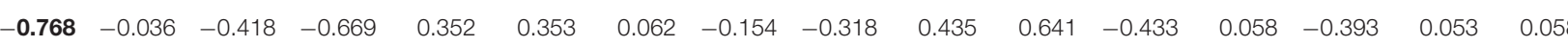

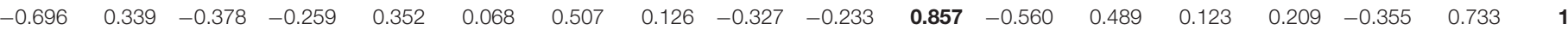

SOD-20 dS/m-0.670

$-0.723-0.074-0.664-0.665-0.25$

Values in bold are different from 0 with a significance level alpha $=0.05$. 


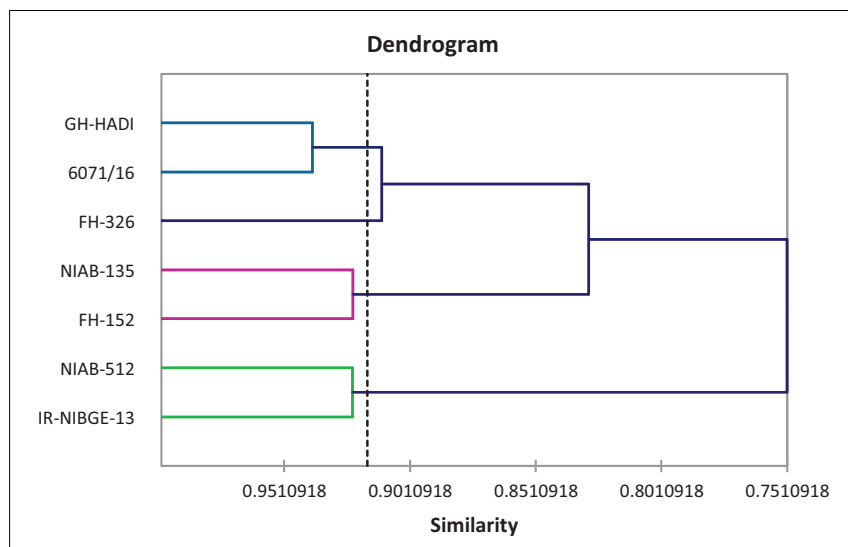

FIGURE 14 | Tree diagram based on biochemical traits for different cotton genotypes under control and salt stress conditions.

TABLE 18 | Distribution of cotton genotypes in different clusters.

\begin{tabular}{ll}
\hline Cluster & Genotypes \\
\hline I & FH-326 \\
II & GH-HADI, 6071/16 \\
III & FH-152, NIAB-135 \\
IV & IR-NIBGE-13, NIAB-512
\end{tabular}

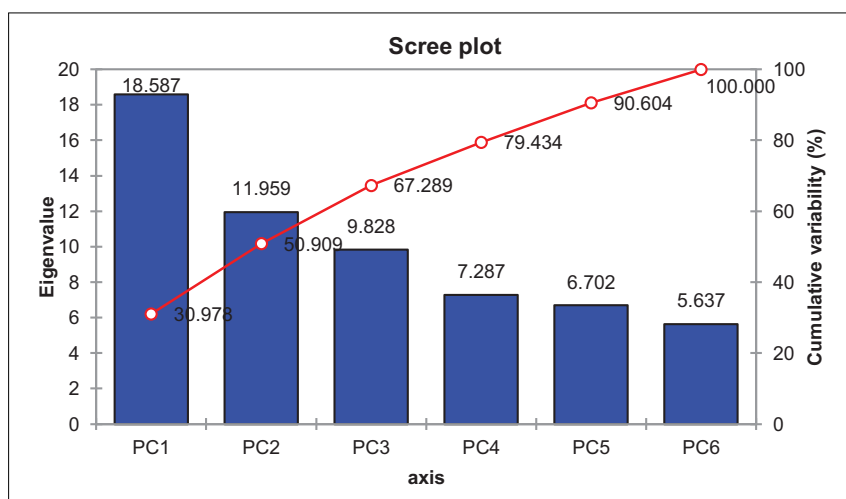

FIGURE 15 | Scree plot between eigenvalues and principal components (PCs) under control and salt stress conditions.

TABLE 19 | Principal component analysis for biochemical traits under control and salt stress conditions in different cotton genotypes.

\begin{tabular}{lcccccc}
\hline & PC1 & PC2 & PC3 & PC4 & PC5 & PC6 \\
\hline Eigenvalue & 18.587 & 11.959 & 9.828 & 7.287 & 6.702 & 5.637 \\
Variability (\%) & 30.978 & 19.931 & 16.380 & 12.145 & 11.171 & 9.396 \\
Cumulative\% & 30.978 & 50.909 & 67.289 & 79.434 & 90.604 & 100.000 \\
\hline
\end{tabular}

shoot length. However, the comparison between the tolerant and susceptible genotype was done with the help of plant fresh and dry weights.

Chlorophyll fluorescence does not change under $\mathrm{NaCl}$ condition (Higbie et al., 2010). Similar results were also found in our experiment. Chlorophyll content was observed to be nonsignificant in all the genotypes between salt-stress-treated and non-treated plants. Under salt stress, closure of stomata and reduction in photosynthetic rate was reported (Brugnoli and Lauteri, 1991). Stomatal closure reduced the $\mathrm{CO}_{2}$ uptake and limited the activity of Rubisco, which ultimately reduced the photosynthesis. In this way, salinity reduced the plant growth and cotton yield (Ahmad and Prasad, 2011). In our experiment, stomatal conductance was significantly decreased in IR-NIBGE16, 6071/16, GH-HADI, and FH-152 but maintained in NIAB135, NIAB-512, SITARA-16, and FH-326. Photosynthetic rate was maintained in all the genotypes with the exception of SITARA-16. According to SSI, IR-NIBGE-13 was found to be more sensitive under $20 \mathrm{dS} / \mathrm{m}$ salt stress condition. Transpiration rate decreased under stress conditions. However, the tolerant cotton genotypes have more transpiration rate under salinity than sensitive genotypes (Dong et al., 2020). In our study, most genotypes showed decrease in transpiration rate under stress conditions. Transpiration rate remained the same in FH-326 under stress and non-stress conditions. Thus, on the basis of SSI and STI, 6071/16 found to be tolerant under $15 \mathrm{dS} / \mathrm{m}$ but sensitive under $20 \mathrm{dS} / \mathrm{m}$ salt stress. Similarly, transpiration rate was significantly decreased in IR-NIBGE-13 under $20 \mathrm{dS} / \mathrm{m}$ salt stress. In NIAB-512 and NIAB-135, maintained transpiration rate under stress conditions was observed.

Salinity stress significantly increased $\mathrm{Na}^{+} / \mathrm{K}^{+}$ratio in cotton (Cramer et al., 1987; Ibrahim et al., 2019). $\mathrm{NaCl}$ treatment affected significantly ionic homeostasis in plant, i.e., $\mathrm{Na}^{+}, \mathrm{K}^{+}, \mathrm{Cl}$, $\mathrm{Zn}, \mathrm{Mn}, \mathrm{N}$, and $\mathrm{Na}^{+} / \mathrm{K}^{+}$ratio (Cramer et al., 1987; Ashraf and Ahmad, 2000; Munns and Tester, 2008; Higbie et al., 2010). $\mathrm{Na}^{+}$ content found to be increased in $\mathrm{NaCl}$-treated plants compared to non-NaCl-treated plants. Moreover, significant differences in $\mathrm{Na}^{+}, \mathrm{K}^{+}$, and $\mathrm{Na}^{+} / \mathrm{K}^{+}$ratio was also observed among the genotypes. In IR-NIBGE-13 and 6071/16, $\mathrm{Na}^{+}$ion accumulated more in leaves as compared to $\mathrm{K}^{+}$ion under stress conditions, and increased in $\mathrm{Na}^{+} / \mathrm{K}^{+}$ratio was also observed. $\mathrm{Na}^{+}$content remained the same in SITARA-16, GH-HADI, and FH-152 under stress and non-stress conditions. $\mathrm{K}^{+}$concentration significantly decreased in IR-NIBGE-16 and FH-152. $\mathrm{Na}^{+}$accumulation in leaves observed a linear increase up to $20 \mathrm{dS} / \mathrm{m}$. Contrary, $\mathrm{K}^{+}$ concentrations remained stable in all the genotypes except FH152 and IR-NIBGE-13. Tolerant genotypes had low $\mathrm{Na}^{+} / \mathrm{K}^{+}$ ratio as compared to susceptible genotypes. The maximum value recorded for $\mathrm{K}^{+}$ion in CIM-779 at $20 \mathrm{dS} / \mathrm{m}$ salt stress condition. $\mathrm{Na}^{+} / \mathrm{K}^{+}$ratio was significantly increased in IRNIBGE-16, FH-152, FH-326, and 6071/16. $\mathrm{Na}^{+} / \mathrm{K}^{+}$ratio was maintained in NIAB-512, NIAB-135, SITARA-16 CIM-602, and CIM-779 under stress conditions.

Salt stress is known to cause the oxidative stress in plants, which results in oxidation of many cellular compounds by increased production of ROS and lipid peroxidation of plasma membrane (Ibrahim et al., 2019). Natural enzymatic antioxidants act as scavengers against these reactive oxygen species like SOD (Gupta and Huang, 2014). SOD converts the $\mathrm{O}^{2-}$ into $\mathrm{H}_{2} \mathrm{O}_{2}$ and $\mathrm{O}_{2}$. On the other hand, in peroxisomes, $\mathrm{H}_{2} \mathrm{O}_{2}$ is converted into $\mathrm{H}_{2} \mathrm{O}$ and $\mathrm{O}_{2}$ by the action of CAT. $\mathrm{H}_{2} \mathrm{O}_{2}$ can also be reduced by the action of peroxidase, 
Biplot (axes PC1 and PC2: $50.91 \%$ )

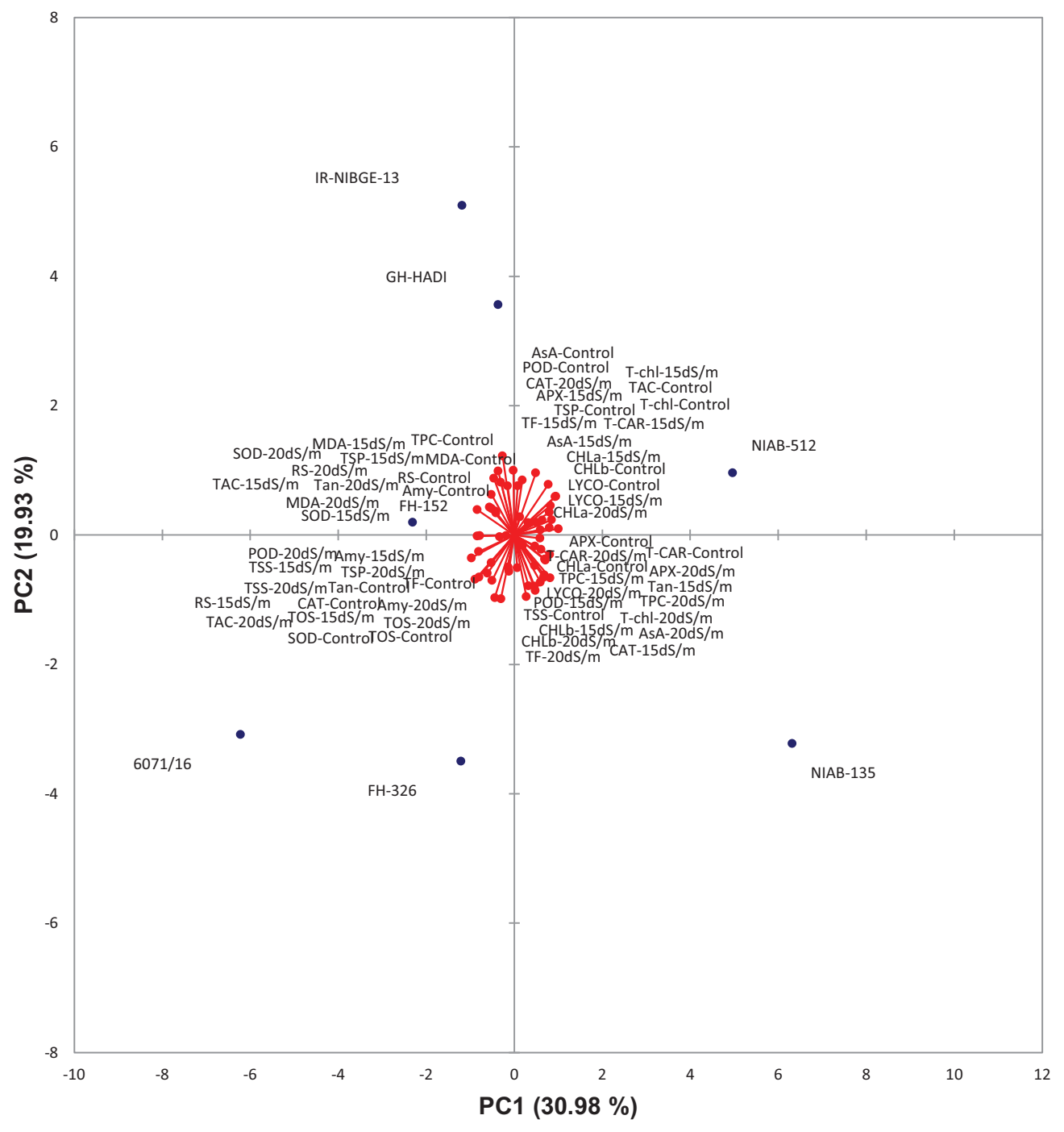

FIGURE 16 | Biplot illustration of all the genotypes under control and salt stress conditions.

as it provides various electron donors for the reduction in ROS (Alscher et al., 2002). Under normal conditions, in photosynthesis, the exited electrons move in electron transport chain (ETC) in thylakoid membrane, converting the oxidize form of NADP + into its reduced NADPH form at photosystem I (PSI). However, under stress, ETC overloaded with the electrons from the photolysis caused the overproduction of ROS, i.e., $\mathrm{O}^{2-}$. This reactive oxygen species converted into $\mathrm{H}_{2} \mathrm{O}_{2}$ by the action of SOD and rapidly detoxify by APX and CAT reaction into stable molecules, i.e., $\mathrm{H}_{2} \mathrm{O}$ and $\mathrm{O}_{2}$ (Ahammed et al., 2018; Kohli et al., 2019). Thus, the decrease in $\mathrm{CO}_{2}$ fixation leads to ROS production and how physiological imbalance leads to oxidative stress. Salttreated plants of IR-NIBGE-13 and 6071/16 limit the stomatal conductance and photosynthetic activity encountered the more oxidative stress.
In plant, SOD and POD content is positively corelated with salt stress tolerance (Gupta and Huang, 2014). Proteomics studies revealed that stressful environment can affect the activity of antioxidants (Zhao et al., 2013). More SOD activity under salinity stress showed that plant is adapted to adverse environmental conditions. Salinity stress caused the reduction in photosynthetic activity, which increased the reactive oxygen species production. Thus, the SOD and POD enzymes are found to be increased in order to detoxify ROS and overcome its generation in plants (Ozgur et al., 2013). In our study, it was found that SOD content significantly increased in IR-NIBGE-13 under salt stress. In NIAB-512, SOD content was significantly increased under 15 $\mathrm{dS} / \mathrm{m}$ salt stress and decreased in FH-326, under stress conditions. SOD content was significantly increased in GH-HADI under $20 \mathrm{dS} / \mathrm{m}$ salt stress. Similarly, it was maintained in FH-152 under salt stress and non-stress conditions. For POD activity, 
a significant increase was observed under salt stress conditions in GH-HADI, NIAB-135, and FH-152. Similarly, a significant decrease in POD activity in some genotypes like NIAB-512 was observed. In 6071/16 genotype, a significant increase in POD activity was observed under $20 \mathrm{dS} / \mathrm{m}$ salt condition. POD activity was maintained in IR-NIBGE-13 under stress and nonstress conditions.

Ascorbate peroxidase and CAT activity is also reported to be increased in cotton plants when exposed to salinity in order to cope with ROS production and protect plant from oxidative damage (Sekmen et al., 2014; Abdelraheem et al., 2019). In our experiment, increased level of APX was observed in tolerant genotypes as FH-152 and NIAB-135 under $20 \mathrm{dS} / \mathrm{m}$ salt stress. GH-HADI showed significant decrease in APX activity under stress conditions. The catalase activity was significantly increased in NIAB-135 and reduced in 6071/16 and FH-152 under salt stress conditions. In NIAB-512 and GH-HADI, CAT activity was significantly increased under $20 \mathrm{dS} / \mathrm{m}$ compared with that under $15 \mathrm{dS} / \mathrm{m}$ salt stress condition, in which it was significantly decreased. CAT activity increased significantly under $20 \mathrm{dS} / \mathrm{m}$ in IR-NIBGE-13. APX and CAT, together with SOD, performed well in scavenging process of oxidants (Abdelraheem et al., 2019).

According to proteomic studies, CAT activity was decreased in prolonged period of salt stress due to decrease in CAT levels (Zhao et al., 2013). Similar behaviors were also reported for MDA content, as with increase in salt concentration and stress duration, MDA and CAT activity reduced. However, in our experiment, MDA content was increased under severe salt stress condition, as MDA is a product of lipid peroxidation of cellular membrane under stress condition (Moussouraki et al., 2019). In NIAB-135 and IR-NIBGE-13, MDA content was significantly increased under $20 \mathrm{dS} / \mathrm{m}$ but significantly decreased under 15 $\mathrm{dS} / \mathrm{m}$ salt stress conditions. In FH-326, a significant increase in MDA content under stress conditions was observed. The more MDA accumulation indicated higher lipid peroxidation due to salinity stress (Meloni et al., 2003). Antioxidant activity varies from plant to plant. Scientists suggested that there can be many factors for this difference in antioxidant activities in genotypes, which includes difference in stomata closure degree or other responses that change the degree of $\mathrm{CO}_{2}$ fixation or may be the difference that cause the photo-inhibition (Munns and Tester, 2008).

Accumulation of carbohydrates (like sugars) under stress conditions is the one of most important plant response mechanisms in order to attain stress tolerance by osmoprotection, carbon storage, and working against ROS (Kerepesi and Galiba, 2000; Parida et al., 2004). In our experiment, a significant increase was observed in total soluble sugar and amylase in NIAB-135 and 6071/16. However, non-significant result was found for reducing sugars.

The activity of other non-enzymatic antioxidants such as lycopene, AsA, tannins, TOS, and total phenolic content was significantly increased under salt stress conditions in tolerant genotypes, i.e., NIAB-135, NIAB-512, and FH-152. The lesser accumulation of MDA content and higher activity of enzymatic antioxidants such as SOD, POD, and APX under stress-treated plants of NIAB-135, NIAB-512, and FH-152 indicated that these genotypes had adaption capacity for salinity stress in comparison with sensitive genotypes, i.e., IR-NIBGE-13 and $6071 / 16$. The bioplot analysis revealed that NIAB-135, 6071/16, FH-326, IR-NIBGE-13, and GH-HADI were highly dispersed from the origin point and had high genetic variability, whereas FH-152 was very close to the traits, i.e., Amy, RS, TPC, and MDA (under control); SOD, TAC, MDA, and TSP (under $15 \mathrm{dS} / \mathrm{m}$ ); and MDA, Tan, SOD, and RS (under $20 \mathrm{dS} / \mathrm{m}$ ). Similarly, NIAB-512 was closed to the LYCO, TAC, TSP, AsA, and CHL-b (under control); LYCO, CHL-a, TF, APX, T-chl, and AsA (under $15 \mathrm{dS} / \mathrm{m}$ ); and CAT, TSP, and CHL-a (under $20 \mathrm{dS} / \mathrm{m}$ ).

\section{CONCLUSION}

Salinity tolerance mechanism involves many complex responses at cellular, metabolical, physiological, biochemical, and molecular levels. As an overall conclusion, the present study revealed that cotton genotypes had significant variations for morphophysiological and biochemical traits under salinity stress. The observed salt tolerance was corelated with plant biomass maintenance (morphological), photosynthetic rate, and ionic homeostasis $\left(\mathrm{K}^{+} / \mathrm{Na}^{+}\right.$ratio, physiological) and biochemical stress marker regulations. From the data presented, after a series of experiments, we found that out of the tested genotypes, NIAB135, NIAB-512, and FH-152 could be used to develop breeding strategies for improvement of salinity tolerance in cotton.

\section{DATA AVAILABILITY STATEMENT}

The raw data supporting the conclusions of this article will be made available by the authors, without undue reservation.

\section{AUTHOR CONTRIBUTIONS}

WM did the overall execution of the experiment, analytical work, collection of data after morpho-physiological and biochemical analysis of leaves, organization of resulting data, and writing up and revision of manuscript. $\mathrm{AH}$ contributed to the planning, designing and finalization of basic idea of experiment and overall supervision during analytical work, carried out the statistical analysis of data using XL-STAT software, did the presentation of resulting data in the form of graphs, and revised and finalized the manuscript. MK did the arrangement and provision of cotton seeds, contributed in study basic idea and planning of glass house experiment, and revised and finalized the manuscript. All authors contributed to the article and approved the submitted version. 


\section{REFERENCES}

Abdelraheem, A., Esmaeili, N., O'Connell, M., and Zhang, J. (2019). Progress and perspective on drought and salt stress tolerance in cotton. Ind. Crops Products 130, 118-129. doi: 10.1016/j.indcrop.2018. 12.070

Ahammed, G. J., Li, Y., Li, X., Han, W.-Y., and Chen, S. (2018). Epigallocatechin3-gallate alleviates salinity-retarded seed germination and oxidative stress in tomato. J. Plant Growth Regul. 37, 1349-1356. doi: 10.1007/s00344-018-9849-0

Ahmad, P., and Prasad, M. N. V. (2011). Abiotic Stress Responses in Plants: Metabolism, Productivity and Sustainability. Berlin: Springer Science \& Business Media.

Ainsworth, E. A., and Gillespie, K. M. (2007). Estimation of total phenolic content and other oxidation substrates in plant tissues using FolinCiocalteu reagent. Nat. Protocols 2, 875-877. doi: 10.1038/nprot. 2007.102

Ali, M. A., Farooq, J., Batool, A., Zahoor, A., Azeem, F., Mahmood, A., et al. (2019). Cotton Production in Pakistan. Hoboken, NJ: wiley online library.

Alscher, R. G., Erturk, N., and Heath, L. S. (2002). Role of superoxide dismutases (SODs) in controlling oxidative stress in plants. J. Exp. Botany 53, 1331-1341. doi: 10.1093/jexbot/53.372.1331

Apse, M. P., Aharon, G. S., Snedden, W. A., and Blumwald, E. (1999). Salt tolerance conferred by overexpression of a vacuolar $\mathrm{Na}+\mathrm{H}+$ antiport in Arabidopsis. Science 285, 1256-1258. doi: 10.1126/science.285.5431.1256

Arnon, D. I. (1949). Copper enzymes in isolated chloroplasts. polyphenoloxidase in Beta vulgaris. Plant Physiol. 24, 1-15. doi: 10.1104/pp.24.1.1

Ashraf, M., and Ahmad, S. (2000). Influence of sodium chloride on ion accumulation, yield components and fibre characteristics in salt-tolerant and salt-sensitive lines of cotton (Gossypium hirsutum L.). Field Crops Res. 66, 115-127. doi: 10.1016/s0378-4290(00)00064-2

Aslam, M., Basra, S., Maqbool, M. A., Bilal, H., UZaman, Q., and Bano, S. (2013). Physio-chemical distinctiveness and metroglyph analysis of cotton genotypes at early growth stage under saline hydroponics. Int. J. Agricul. Biol. 15:2013.

Athar, H., and Ashraf, M. (2009). "Strategies for crop improvement against salinity and drought stress: an overview," in Salinity and Water Stress, eds M. Ashraf, M. Ozturk, and H.-u.-R. Athar (Berlin: Springer), 1-16. doi: 10.1007/978-1-40209065-3_1

Bartels, D., and Sunkar, R. (2005). Drought and salt tolerance in plants. Crit. Rev. Plant Sci. 24, 23-58.

Beers, R. F., and Sizer, I. W. (1952). A spectrophotometric method for measuring the breakdown of hydrogen peroxide by catalase. J. Biol. Chem. 195, 133-140. doi: 10.1016/s0021-9258(19)50881-x

Bolek, Y. (2010). Predicting cotton seedling emergence for cold tolerance: Gossypium hirsutum L. Notulae Botanicae Horti Agrobotanici Cluj-Napoca 38, 134-138.

Bradford, N. (1976). A rapid and sensitive method for the quantitation microgram quantities of a protein isolated from red cell membranes. Anal. Biochem. 72, 248-254. doi: 10.1016/0003-2697(76)90527-3

Brugnoli, E., and Lauteri, M. (1991). Effects of salinity on stomatal conductance, photosynthetic capacity, and carbon isotope discrimination of salttolerant (Gossypium hirsutum L.) and salt-sensitive (Phaseolus vulgaris L.) C3 non-halophytes. Plant Physiol. 95, 628-635. doi: 10.1104/pp. 95.2.628

Campbell, B., Saha, S., Percy, R., Frelichowski, J., Jenkins, J. N., Park, W., et al. (2010). Status of the global cotton germplasm resources. Crop Sci. 50, 11611179 .

Chinnusamy, V., Jagendorf, A., and Zhu, J.-K. (2005). Understanding and improving salt tolerance in plants. Crop Sci. 45, 437-448. doi: 10.2135/ cropsci2005.0437

Cramer, G. R., Lynch, J., Läuchli, A., and Epstein, E. (1987). Influx of Na+, K+, and $\mathrm{Ca} 2+$ into roots of salt-stressed cotton seedlings: effects of supplemental Ca2+. Plant Physiol. 83, 510-516.

Dhindsa, R. S., Plumb-Dhindsa, P., and Thorpe, T. A. (1981). Leaf senescence: correlated with increased levels of membrane permeability and lipid peroxidation, and decreased levels of superoxide dismutase and catalase. J. Exp. Botany 32, 93-101.

Dietz, K.-J., Tavakoli, N., Kluge, C., Mimura, T., Sharma, S., Harris, G., et al. (1969). Significance of the V-type ATPase for the adaptation to stressful growth conditions and its regulation on the molecular and biochemical level. J. Exp. Botany 52, 1969-1980.

Dixit, V., Pandey, V., and Shyam, R. (2001). Differential antioxidative responses to cadmium in roots and leaves of pea (Pisum sativum L. cv. Azad). J. Exp. Botany $52,1101-1109$.

Dong, Y., Hu, G., Yu, J., Thu, S. W., Grover, C. E., Zhu, S., et al. (2020). Salt-tolerance diversity in diploid and polyploid cotton. Plant J. 101, 1135-1151.

Dubois, M., Gilles, K., Hamilton, J., Rebers, P., and Smith, F. (1956). Phenol sulphuric acid method for total carbohydrate. Anal. Chem. 26:350.

Erel, O. (2005). A new automated colorimetric method for measuring total oxidant status. Clin. Biochem. 38, 1103-1111. doi: 10.1016/j.clinbiochem.2005. 08.008

Fernandez, G. C. (1993). "Effective selection criteria for assessing plant stress tolerance," in Proceedings of the International Symposium on Adaptation of Vegetables and other Food Crops Intemperature and Water Stress, ed. C. G. Kuo (Tainan: AVRDC Publication), 257-270.

Fischer, R., and Maurer, R. (1978). Drought resistance in spring wheat cultivars. I. Grain yield responses, Australian. J. Agricul. Res. 29, 897-912. doi: 10.1071/ AR9780897

Giaanopolitis, N., and Ries, S. (1977). Superoxide dismutase I, Occurrence in higher plants. Plant Physio1. 59, 309-314. doi: 10.1104/pp.59.2.309

Gouia, H., Ghorbal, M. H., and Touraine, B. (1994). Effects of $\mathrm{NaCl}$ on flows of $\mathrm{N}$ and mineral ions and on NO3-reduction rate within whole plants of salt-sensitive bean and salt-tolerant cotton. Plant Physiol. 105, 1409-1418. doi: 10.1104/pp.105.4.1409

Gupta, B., and Huang, B. (2014). Mechanism of salinity tolerance in plants: physiological, biochemical, and molecular characterization. Int. J. Genom. 2014:701596. doi: 10.1155/2014/701596

Hameed, A., Iqbal, N., Malik, S. A., Syed, H., and Ahsanul-Haq, M. (2005). Age and Organ Specific Accumulation of Ascorbate in Wheat (Triticum aestivum L.) Seedlings Grown Under Etiolation Alone and in Combination with Oxidative Stress. Toronto: University of toronto.

Heath, R. L., and Packer, L. (1968). Photoperoxidation in isolated chloroplasts: i. kinetics and stoichiometry of fatty acid peroxidation. Arch. Biochem. Biophys. 125, 189-198. doi: 10.1016/0003-9861(68)90654-1

Higbie, S. M., Wang, F., Stewart, J. M., Sterling, T. M., Lindemann, W. C., Hughs, E., et al. (2010). Physiological response to salt $(\mathrm{NaCl})$ stress in selected cultivated tetraploid cottons. Int. J. Agronomy 2010:643475. doi: 10.1155/2010/64 3475

Hiraga, S., Sasaki, K., Ito, H., Ohashi, Y., and Matsui, H. (2001). A large family of class III plant peroxidases. Plant Cell Physiol. 42, 462-468. doi: 10.1093/pcp/ pce061

Hu, Y., Chen, J., Fang, L., Zhang, Z., Ma, W., Niu, Y., et al. (2019). Gossypium barbadense and Gossypium hirsutum genomes provide insights into the origin and evolution of allotetraploid cotton. Nat. Genet. 51:739. doi: 10.1038/s41588019-0371-5

Hussain, S., Shaukat, M., Ashraf, M., Zhu, C., Jin, Q., and Zhang, J. (2019). “Salinity stress in arid and semi-arid climates: effects and management in field crops," in Climate Change and Agriculture, ed. S. Hussain (London: IntechOpen). doi: 10.5772/intechopen. 87982

Ibrahim, W., Qiu, C. W., Zhang, C., Cao, F., Shuijin, Z., and Wu, F. (2019). Comparative physiological analysis in the tolerance to salinity and drought individual and combination in two cotton genotypes with contrasting salt tolerance. Physiol. Plantarum 165, 155-168. doi: 10.1111/ppl.12791

Jabran, K., Ul-Allah, S., Chauhan, B. S., and Bakhsh, A. (2019). An Introduction to Global Production Trends and Uses, History and Evolution, and Genetic and Biotechnological Improvements in cotton. Hoboken, NJ: wiley online library. doi: $10.1002 / 9781119385523 . c h 1$

Kerepesi, I., and Galiba, G. (2000). Osmotic and salt stress-induced alteration in soluble carbohydrate content in wheat seedlings. Crop Sci. 40, 482-487. doi: $10.2135 /$ cropsci2000.402482x

Khan, A., Qureshi, R., Ahmad, N., and Rashid, A. (1995). Response of cotton cultivars to salinity at various growth development stages. Sarhad J. Agricult. $11,729-731$.

Kohli, S. K., Khanna, K., Bhardwaj, R., Abd_Allah, E. F., Ahmad, P., and Corpas, F. J. (2019). Assessment of subcellular ROS and NO metabolism in higher plants: multifunctional signaling molecules. Antioxidants 8:641. doi: 10.3390/ antiox8120641 
Loka, D. A., Oosterhuis, D. M., and Ritchie, G. L. (2011). Water-deficit stress in cotton. Stress Physiol. Cotton 7, 37-72.

Maas, E. V., and Hoffman, G. J. (1977). Crop salt tolerance-current assessment. J. Irrigat. Drainage Div. 103, 115-134. doi: 10.1061/JRCEA4.0001137

Maathuis, F. J. (2013). Sodium in plants: perception, signalling, and regulation of sodium fluxes. J. Exp. Botany 65, 849-858. doi: 10.1093/jxb/ert326

Maehly, A., and Chance, B. (1955). Assay of catalases and peroxidases, in methods in enzymology. Methods Enzymol 2, 764-775. doi: 10.1016/S0076-6879(55) 02300-8

Meloni, D. A., Oliva, M. A., Martinez, C. A., and Cambraia, J. (2003). Photosynthesis and activity of superoxide dismutase, peroxidase and glutathione reductase in cotton under salt stress. Environ. Exp. Botany 49, 69-76. doi: 10.1016/S0098-8472(02)00058-8

Miller, G., Suzuki, N., Ciftci-Yilmaz, S., and Mittler, R. (2010). Reactive oxygen species homeostasis and signalling during drought and salinity stresses. Plant Cell Environ. 33, 453-467. doi: 10.1111/j.1365-3040.2009.02041.x

Miller, G. L. (1959). Use of dinitrosalicylic acid reagent for determination of reducing sugar. Anal. Chem. 31, 426-428. doi: 10.1021/ac60147a030

Moussouraki, M.-A., Eleni, T., Velliou, A., Goufa, M., Psychogiou, M., Papadakis, I. E., et al. (2019). Growth, physiological and biochemical responses of two greek cotton cultivars to salt stress and their impact as selection indices for salt tolerance. Notulae Botanicae Horti Agrobotanici Cluj-Napoca 47, 706-715. doi: /10.15835/nbha47311463

Muchate, N. S., Nikalje, G. C., Rajurkar, N. S., Suprasanna, P., and Nikam, T. D. (2016). Plant salt stress: adaptive responses, tolerance mechanism and bioengineering for salt tolerance. Botan. Rev. 82, 371-406. doi: 10.1007/s12229016-9173-y

Munns, R., and Tester, M. (2008). Mechanisms of salinity tolerance. Annu. Rev. Plant Biol. 59, 651-681. doi: 10.1146/annurev.arplant.59.032607.092911

Ozgur, R., Uzilday, B., Sekmen, A. H., and Turkan, I. (2013). Reactive oxygen species regulation and antioxidant defence in halophytes. Funct. Plant Biol. 40, 832-847. doi: 10.1071/FP12389

Parida, A. K., Das, A. B., and Mohanty, P. (2004). Investigations on the antioxidative defence responses to $\mathrm{NaCl}$ stress in a mangrove, Bruguiera parviflora: differential regulations of isoforms of some antioxidative enzymes. Plant Growth Regul. 42, 213-226. doi: 10.1023/B:GROW.0000026508.63288.39

Peng, Z., He, S., Sun, J., Pan, Z., Gong, W., Lu, Y., et al. (2016). Na+ compartmentalization related to salinity stress tolerance in upland cotton (Gossypium hirsutum) seedlings. Sci. Rep. 6:34548. doi: 10.1038/srep34548

Sekmen, A. H., Ozgur, R., Uzilday, B., and Turkan, I. (2014). Reactive oxygen species scavenging capacities of cotton (Gossypium hirsutum) cultivars under combined drought and heat induced oxidative stress. Environ. Exp. Botany 99, 141-149. doi: 10.1016/j.envexpbot.2013.11.010

Sharif, I., Aleem, S., Farooq, J., Rizwan, M., Younas, A., Sarwar, G., et al. (2019). Salinity stress in cotton: effects, mechanism of tolerance and its management strategies. Physiol. Mol. Biol. Plants 25, 807-820. doi: 10.1007/s12298-01900676-2

Shi, H., and Zhu, J.-K. (2002). Regulation of expression of the vacuolar $\mathrm{Na}+/ \mathrm{H}+$ antiporter gene AtNHX1 by salt stress and abscisic acid. Plant Mol. Biol. 50, 543-550. doi: 10.1023/A:1019859319617

Varavinit, S., Chaokasem, N., and Shobsngob, S. (2002). Immobilization of a thermostable alpha-amylase. Sci. Asia 28, 247-251. doi: 10.2306/ scienceasia1513-1874.2002.28.247

Wang, Q., Fang, L., Chen, J., Hu, Y., Si, Z., Wang, S., et al. (2015). Genomewide mining, characterization, and development of microsatellite markers in Gossypium species. Sci. Rep. 5:10638. doi: 10.1038/srep 10638

Wang, Z., Wang, J., Bao, Y., Wu, Y., and Zhang, H. (2011). Quantitative trait loci controlling rice seed germination under salt stress. Euphytica 178, 297-307. doi: 10.1007/s10681-010-0287-8

Xiong, L., and Zhu, J. K. (2002). Molecular and genetic aspects of plant responses to osmotic stress. Plant Cell Environ. 25, 131-139. doi: 10.1046/j.1365-3040.2002. 00782.x

Zhang, T., and Lin, W. (2014). Metal-organic frameworks for artificial photosynthesis and photocatalysis. Chem. Soc. Rev. 43, 5982-5993. doi: 10.1039/ C4CS00103F

Zhao, Q., Zhang, H., Wang, T., Chen, S., and Dai, S. (2013). Proteomics-based investigation of salt-responsive mechanisms in plant roots. J. Proteom. 82, 230-253. doi: 10.1016/j.jprot.2013. 01.024

Zhong, H., and Läuchli, A. (1993). Spatial and temporal aspects of growth in the primary root of cotton seedlings: effects of $\mathrm{NaCl}$ and $\mathrm{CaCl}$ 2. J. Exp. Botany 44, 763-771. doi: 10.1093/jxb/44.4.763

Zhu, J.-K. (2001). Plant salt tolerance. Trends Plant Sci. 6, 66-71. doi: 10.1016/ S1360-1385(00)01838-0

Zhu, J.-K. (2003). Regulation of ion homeostasis under salt stress. Curr. Opin. Plant Biol. 6, 441-445. doi: 10.1016/S1369-5266(03) 00085-2

Conflict of Interest: The authors declare that the research was conducted in the absence of any commercial or financial relationships that could be construed as a potential conflict of interest.

Copyright (c) 2021 Munawar, Hameed and Khan. This is an open-access article distributed under the terms of the Creative Commons Attribution License (CC BY). The use, distribution or reproduction in other forums is permitted, provided the original author(s) and the copyright owner(s) are credited and that the original publication in this journal is cited, in accordance with accepted academic practice. No use, distribution or reproduction is permitted which does not comply with these terms. 